\title{
EL DEVENIR DE LA APERTURA DE TIENDAS Y LA CONSECUCIÓN DEL MAGISTERIO ARTESANO COMO “PROXY-DATA” ECONÓMICO URBANO EN EL BURGOS DEL SETECIENTOS
}

\author{
FRANCISCO SANZ DE LA HIGUERA
}

\begin{abstract}
RESUMEN: Estas páginas pergeñan un análisis crítico de las solicitudes de licencia para la apertura de tiendas en el Burgos del siglo XVIII, parámetro combinado con la diacronía de la obtención de la maestría artesanal a través de las cartas de examen. Ello posibilita, a mi juicio, una reconstrucción aproximativa del clima económico existente en la ciudad castellana a lo largo de dicha centuria. Tiendas y cartas de examen se conjugan para ofrecernos un "Proxy-data" diagnóstico del panorama, positivo o negativo, subyacente a la economía urbana, y de sus patologías climáticas y productivas en lo agrario. El zig-zag de las series nos aproxima, también, a las palpitaciones del consumo, de la oferta y demanda generada por los habitantes de Burgos, mayor entre los más privilegiados y más paupérrima entre los menos afortunados.
\end{abstract}

PALABRAS CLAVES: Tienda, carta de examen, "Proxy-data", Burgos.

\section{THE DEVELOPMENT OF THE OPENING OF STORES AND THE ACHIEVEMENT OF ARTISAN TEACHING LIKE URBAN ECONOMIC "PROXY-DATA" IN THE EIGHTEENTH CENTURY BURGOS}

\begin{abstract}
These pages provide a critical analysis of license applications for the opening of stores in the eighteenth-century Burgos, a parameter combined with the diachrony of obtaining artisan mastery through examination letters. This makes possible, in my opinion, an approximate reconstruction of the economic atmosphere existing in the Castilian city throughout this century. Shops and examination letters are combined to offer us a "Proxydata" diagnosis of the landscape, positive or negative, underlying the urban economy, and its climatic and productive pathologies in the agrarian field. The zig-zag of the series also brings us closer to the palpitations of consumption, of the supply and demand generated by the inhabitants of Burgos, bigger among the most privileged and more impoverished among the less fortunate.
\end{abstract}

KEYWORDS: Shop, examination letter, "Proxy-data", Burgos. 


\section{Introducción, fuentes documentales y aproximación bibliográfica}

La reconstrucción del devenir de las solicitudes de licencia para la apertura de tiendas, por una parte ${ }^{1}$ y del acceso al rango de maestro artesanal, a través de la obtención de la correspondiente "Carta de examen", por otra, y, a su vez, el contraste, crítico, de ambas magnitudes a lo largo del siglo XVIII, va a ser traída a colación en estas páginas. Ese planteamiento diacrónico posibilita, a mi juicio, el disponer de potentes herramientas con las que examinar las potencialidades de negocio existentes en el Setecientos en la ciudad de Burgos. Son "barómetros" que diagnostican las tendencias económicas. En la práctica, los pequeños "empresarios"3 que solicitaban, y conseguían, abrir al público sus talleres artesanos, mesones, figones, confiterías, tiendecillas, ... materializaban en sus personas y hogares, en la medida de lo posible, el palpitar de las necesidades de consumo que se suscitaban en la ciudad. Evidentemente, en todo ello influyen, de manera decidida, la evolución del volumen de población y la abundancia, o déficit, de los productos para vender. Un mayor número de habitantes, una más significativa capacidad de consumo y de disponibilidad de dinero en efectivo y una dinámica positiva, o negativa, en la apertura de tiendas y de talleres inducen a pergeñar un análisis en el que se intuyan pálpitos de crecimiento, o de crisis, económica.

Tiendas y talleres patentizan, en la creación de sus instalaciones, el clima económico, de oferta y demanda, de la ciudad del Antiguo Régimen. Eran “emprendedores” que leían, entre líneas, cuáles eran las disponibilidades monetarias de los residentes y sus capacidades adquisitivas. No hemos de olvidar, en ningún caso, que se trata, aún, de sociedades con un importante sesgo agrícola. El acontecer climático, y meteorológico, generaba substanciales efervescencias y crisis de producción, las cuales afectaron, sin duda, a las rentas y fortunas de los hogares urbanos. También es significativo el hecho de que se trataba de sociedades urbanas muy estratificadas, con poderosos, y nutridos, segmentos de pobreza y de debilidad económica, por un lado, "clases medias" muy endebles, por otro, y, a la postre, una casta

\footnotetext{
1 Archivo Municipal de Burgos (AMB). Actas de Gobierno (AG), Actas de Abastos (AA) y Actas de la Junta de Propios y Arbitrios (JPA). 1700-1800.

2 Archivo Histórico Provincial de Burgos (AHPB). Concejil. 1728-1778 y AMB. Múltiples Legajos. 1778-1800.

3 Sobre esta problemática véanse, entre otras propuestas, OTAZU, Alfonso (Ed.): Dinero y crédito (Siglos XVI al XIX), Madrid, Moneda y Crédito, 1978, en especial, VILAR, Pierre: "La noción de empresa y de empresario, desde los tiempos modernos a los contemporáneos", pp. 241-248; COMÍN, Alfonso y MARTÍN ACEÑA, Pablo (Eds.): La empresa en la historia de España, Madrid, Editorial Civitas, 1996; HERNÁNDEZ GARCÍA, Ricardo: "Empresa y empresarios en la industria textil de la Tierra de Campos a mediados del siglo XVIII", Anales de Estudios Económicos y Empresariales, 17, 2007, pp. 127-156; GARCÍA RUIZ, José Luís y MANERA ERBINA, Carlos Pablo (Dirs.): Historia empresarial de España: un enfoque regional en profundidad, Madrid, Editorial Empresarial, 2006 y OCAMPO SUÁREZ-VALDÉS, Joaquín (Ed.): Empresas y empresarios en el norte de España (siglo XVIII), Oviedo, Ediciones Trea, 2012.
} 
aristocrática, reducida en dimensiones, de notable poder económico, político y de consumo ${ }^{4}$. En función de la hipótesis planteada - ¿podemos acercarnos de alguna manera a los sesgos de oferta artesanal y de servicios en la ciudad del Setecientos? -, la tesis que se defiende en estas páginas se concreta en la configuración de las tiendas y talleres como "proxy-data" económico, a través del cual visualizar el panorama de oferta y demanda en una ciudad castellana del Antiguo Régimen. "La recuperación económica fue lenta, tortuosa y discontinua en el interior peninsular [no sólo] en la segunda mitad del siglo XVII” [sino también en buena parte del XVIII] $]^{5}$.

Un fenómeno muy interesante, factor esencial en la dinamización comercial del XVIII, "fue el de la multiplicación del número de tiendas, un tipo de establecimiento menos especializado que la tienda gremial, el cual se extendió primero por Cataluña, difundiéndose más tarde por el resto del país”.

Ambas magnitudes, las solicitudes de licencia para la apertura de tiendas y la obtención de la maestría artesanal merced a la consecución de la carta de examen adecuada, han sido recopiladas a través del seguimiento intensivo, y completo, de dos fuentes documentales disponibles en los archivos de la ciudad de Burgos.

En primera instancia, los Libros de Actas del Concejo - Ayuntamiento - burgalés entre 1700 y 1800. Es imprescindible señalar que, afortunadamente, disponemos de toda la serie, sin ninguna merma ocasional, circunstancia que evita una dramática pérdida de información y magnifica, en sí misma, el acceso al acontecer de múltiples eventos ocurridos en su tejido urbano a lo largo del Setecientos. En sus folios hemos efectuado una recopilación completa de las solicitudes de licencia para la apertura de tiendas a las autoridades municipales. Se indica, en cada una de ellas, la filiación del peticionario, el tipo de "tienda" - a qué se iban a dedicar y en qué condiciones - y su ubicación en el entramado urbano. En dichas Actas se han localizado también múltiples anotaciones significativas sobre las problemáticas profesionales del artesanado y de los comerciantes, pequeños, medianos y grandes, de la ciudad. También accedemos al devenir de las afectaciones climáticas - sequías, precipitaciones

\footnotetext{
4 "El resultado final de todo ello era una sociedad polarizada: un puñado no pequeño de grandes ricos en un lado; la más absoluta indigencia en el otro, con el agravante de que la Real Hacienda extraía más de los cercanos al polo negro que a los alojados en el polo rosa". CAMARERO BULLÓN, Concepción: "La provincia de Burgos en el siglo de las luces", en Historia de Burgos III (Edad Moderna I), Caja de Ahorros Municipal de Burgos, Torres de Elorz, 1991, pp. 208.

${ }^{5}$ LLOPIS, Enrique y AMARILLA, José Antonio: “Aclarando tintes demasiado oscuros. La economía española en el siglo XVIII”, Cuadernos Dieciochistas, 2018 (en prensa) y MARCOS MARTÍN, Alberto: España en los siglos XVI, XVII y XVIII: Economía y sociedad, Barcelona, Crítica, 2000, pp. 553-706.

${ }^{6}$ MARCOS MARTÍN, Alberto: op. cit., pp. 675
} 
típicas y extraordinarias, fríos, "yelos" y nieves, inundaciones por "avenida", ... - que asolaron al Burgos del XVIII. E igualmente al análisis de la repercusión que las guerras exteriores y conflictos interiores infringían en la economía productiva urbana, en especial, al artesanado, a los servicios públicos habilitados para facilitar el acceso a la comida y otros bienes esenciales - es decir a la logística del abastecimiento urbano - y a los mercaderes, al por mayor (lonjas) o al por menor (tiendas).

En segundo término, la reconstrucción del devenir de las cartas de examen se ha conseguido con la documentación custodiada tanto en el Archivo Histórico Provincial de Burgos, en su sección Concejil, como en el Archivo Municipal de Burgos. Las cartas de examen de 1728-1778 proceden de los legajos de Concejil y las de 1779-1800 del Archivo municipal. Tanto en esta fuente como en la anteriormente citada tenemos la constancia absoluta de que están completas al $100 \%$, dado que se encuentran integradas en un foliado continuo en el que no falta ninguno de sus folios. "El carácter masivo de las actas notariales [y de las Actas del Concejo] - enfatiza Moreno Claverías, y lo comparto sin duda alguna permite la cuantificación y la seriación de datos, lo que permite las comparaciones con otras muestras en el espacio y en tiempo, así como el manejo estadístico"”. En total, tras un arduo rastreo intensivo, y completo, de las fuentes documentales, se han hallado 1.260 cartas de examen y 850 licencias de tiendas ${ }^{8}$.

Además, en el Archivo Diocesano de Burgos, se han recopilado las series existentes de tazmías de las parroquias urbanas y, en concreto, la producción de trigo a lo largo del XVIII ${ }^{9}$. El contraste, dialéctico, entre licencias de tiendas, cartas de examen para la maestría artesanal y volúmenes de trigo nos aproxima a algunos de los principales parámetros de la economía burgalesa del Setecientos.

La palabra "tienda" precisa de una acotación técnica. Es preciso delimitar su tesitura para una idónea utilización. Ha sido hallada en las Actas municipales para traer a colación una tipología variada de establecimientos. Por encima de lo pormenorizado de cada uno de ellos, lo fundamental es que la petición de licencia de tienda, solicitada al Concejo y aceptada

\footnotetext{
${ }^{7}$ MORENO CLAVERÍAS, Belén: “¿Cómo se construye la historia económica? El uso de los documentos notariales para las prácticas de historia económica en el marco del EEES", en IX Encuentro de Didáctica de la Historia Económica, Toledo, 2010, pp. 4 [En línea] WWW. Aehe.es/wp_content/uploads/2010/09/ moreno.pdf (Consulta: 20 de marzo de 2019).

8 Sobre todo ello véase SANZ de la HIGUERA, Francisco: "Procesos de reclutamiento gremial en el Burgos del Setecientos”, en Boletín de la Institución Fernán González (BIFG), 258, 2018, pp. 87-110.

9 Archivo Diocesano de Burgos (ADB). Libros de tazmías de San Martín, San Gil, San Román, San Cosme, San Esteban, Viejarrúa y Cortes (1711-1800).
} 
en los Regimientos ordinarios por los alcaldes y regidores perpetuos, incumbía, según el caso, a establecimientos dedicados al alojamiento ${ }^{10}$, a la bebida ${ }^{11}$, a la venta de mercancías ${ }^{12}$, a la docencia $^{13}$, a los quehaceres de los talleres artesanos y a la sanidad ${ }^{14}$.

Esta reconstrucción histórica tiene varios telones de fondo, a modo de temáticas esenciales - evolución de la economía española del XVIII, devenir de las tiendas y los talleres artesanales, mejora de las redes empresariales,...-. Para su encuadre disponemos de un acervo bibliográfico de referencia, de diferente envergadura. En lo tocante a la economía del Setecientos, hay una excelente relación de trabajos nacionales e internacionales que facilitan conocer el panorama general de la situación económica en esta centuria. Descuellan, entre otras muchas, también excelentes, las propuestas y planteamientos de Llopis Agelán y Sebastián Amarilla ${ }^{15}$, Fernández de Pinedo, Gil Novales y Dérozier ${ }^{16}$, Enciso Recio, González Enciso, Egido López, Barrio Gozalo y Torres Sánchez ${ }^{17}$, Marcos Martín ${ }^{18}$, Vilar ${ }^{19}$, Anes Álvarez ${ }^{20}$, García Sanz ${ }^{21}$, González Enciso ${ }^{22}$, Franch Benavent ${ }^{23}$, Palop ${ }^{24}$, Mantecón Movellán ${ }^{25}$, Fontana Lázaro, Malamud Rikles, Prados de Escotura, Delgado Ribas, Tinoco

\footnotetext{
10 Mesones y posadas.

11 Alojerías, botillerías, tabernas y aguardientes.

12 Tiendas de joyería, abacerías, lonjas de paños y sedas, figones, fruterías y mercerías.

${ }^{13}$ Escuelas de primeras letras.

14 Cirujanos, barberos, sangradores y peluqueros.

15 LLOPIS, Enrique y AMARILLA, José Antonio: $o p$. cit.
}

16 FERNÁNDEZ de PINEDO, Emiliano, GIL NOVALES, Alberto y DÉROZIER, Albert: Centralismo, Ilustración y agonía del Antiguo Régimen (1715-1833), en TUÑÓN de LARA, Manuel (Dir.): Historia de España, Barcelona, Editorial Labor, 1985, tomo 7.

${ }^{17}$ ENCISO RECIO, Luís Miguel, GONZÁLEZ ENCISO, Agustín, EGIDO LÓPEZ, Teófanes, BARRIO GOZALO, Maximiliano y TORRES SÁNCHEZ, Rafael: Los Borbones en el siglo XVIII (1700-1808), en MONTENEGRO DUQUE, Ángel (Coord.): Historia de España, Madrid, Gredos, 1991, tomo 10.

${ }^{18}$ MARCOS MARTÍN, Alberto: op. Cit.

${ }^{19}$ VILAR, Pierre: Cataluña en la España Moderna. 3. La formación del capital comercial, Barcelona, Crítica, 1988.

20 ANES ÁLVAREZ, Gonzalo: Las crisis agrarias en la España moderna, Madrid, Taurus, 1974 y El Antiguo Régimen: Los Borbones, Madrid, Alianza Universidad, 1983.

${ }^{21}$ GARCÍA SANZ, Ángel: Desarrollo y crisis del Antiguo Régimen en Castilla la Vieja. Economia y sociedad en tierras de Segovia de 1500 a 1814, Madrid, Akal, 1977.

22 GONZÁLEZ ENCISO, Agustín: "La economía en el siglo XVIII: Agricultura, industria y comercio", en MONTENEGRO DUQUE, Ángel (Dir.): Historia de Burgos III (Edad Moderna I), Torres de Elorz, Caja de Ahorros Municipal de Burgos, 1991, pp. 269-346.

${ }^{23}$ FRANCH BENAVENT, Ricardo: Crecimiento comercial y enriquecimiento burgués en la Valencia del siglo XVIII, Valencia, Institució Alfons el Magnànim, 1986 y El capital comercial valenciano en el siglo XVIII, Valencia, Monografías y Fuentes, 1989.

${ }^{24}$ PALOP RAMOS, José Miguel: Hambre y lucha antifeudal. Las crisis de subsistencias en Valencia (Siglo XVIII), Madrid, Siglo XXI de España, 1977 y Fluctuaciones de precios y abastecimiento en la Valencia del siglo XVIII, Valencia, Caja de Ahorros y Monte de Piedad de Valencia, 1977.

${ }_{25}$ MANTECÓN MOVELLÁN, Tomás: España en tiempos de Ilustración. Los desafios del siglo XVIII, Madrid, Alianza Editorial, 2013. 
Rubiales y Cuenca Cervera ${ }^{26}$, Helguera Quijano ${ }^{27}$, Carrera Pujal ${ }^{28}$, Labrousse $^{29}$, De Vries ${ }^{30}$ o Zanden $^{31}$. Sobre el caso más específico del comercio y de la apertura, y las problemáticas, de tiendas, contamos con un menor número de estudios, centrados, sobre todo, en el análisis de las transformaciones mercantiles. Véanse, entre otras opciones, los análisis desarrollados por Torra Fernández ${ }^{32}$, Gutiérrez Alonso ${ }^{33}$, Sanz de la Higuera ${ }^{34}$, Dávila Corona ${ }^{35}$, Muñoz Navarro $^{36}$, Mui y Hoh-cheung ${ }^{37}$ o Stobart, Hann y Morgan ${ }^{38}$. Sobre el devenir del acceso a la maestría artesanal la disponibilidad de trabajos es aún menor, y se inclina, en especial, por el análisis de la admisión de los nuevos maestros gremiales. Descuellan, en especial, en Nieto Sánchez ${ }^{39}$, Franch, Muñoz Navarro y Rosado Calatayud ${ }^{40}$, Sola Parera y Yamamichi ${ }^{41}$, Sanz de la Higuera ${ }^{42}$ y Sola Corbacho ${ }^{43}$, entre otras posibilidades.

${ }^{26}$ FONTANA LÁZARO, Joseph, MALAMUD RIKLES, Carlos, PRADOS de ESCOTURA, Leandro, DELGADO RIBAS, José María, TINOCO RUBIALES, Santiago y CUENCA CERVERA, Javier: La economía española al final del Antiguo Régimen: Comercio y colonias, Madrid, Alianza Editorial y Banco de España, 1982.

${ }^{27}$ HELGUERA QUIJANO, Juan: “La economía: Un crecimiento limitado, sobre bases tradicionales", en La Ilustración: Una recuperación incompleta (Siglo XVIII), Valladolid, Ámbito Ediciones, 1986, tomo 8, pp. 56-97.

${ }^{28}$ CARRERA PUJAL, Jaime: Historia de la economia española, Barcelona, Bosch, 1943.

${ }^{29}$ LABROUSSE, Ernest: Fluctuaciones económicas e historia social, Madrid, Tecnos, 1980.

${ }^{30}$ De VRIES, Jan: La economia de Europa en un período de crisis, 1600-1750, Barcelona, Cátedra, 1992.

31 Van ZANDEN, Jan Luiten: "Una estimación del crecimiento económico en la Edad Moderna”, Investigaciones de Historia Económica, 2, 2005, pp. 9-38.

32 TORRA FERNÁNDEZ, Lidia: "Botigues de teixitis, crèdit comercial i crèdit al consum: Xarxes comercials a la Catalunya del segle XVIII", Recerques, 41, 2001, pp. 5-30 y "Las botigues de teles de Barcelona: aportación al estudio de la oferta de tejidos y del crédito al consumo (1650-1800)", Revista de Historia Económica, no extra 4, 2003, pp, 89-105.

33 GUTIÉRREZ ALONSO, Adriano: "El comercio interior en Burgos durante la época moderna", en PEÑA PÉREZ, Francisco Javier y PAYO HERNANZ, René (Coords.): Historia del comercio de Burgos, Burgos, Federación de Empresarios de Comercio de Burgos, 2005, p. 167-185.

${ }^{34}$ SANZ de la HIGUERA, Francisco: "Perspectivas de negocio y cultura material en una saga de comerciantes burgaleses del XVIII. Los Bernáldez de Velasco", Boletín de la Institución Fernán González. (BIFG), 255, 2017, pp. 361-384.

${ }^{35}$ DÁVILA CORONA, Rosa María: "Transformación y permanencia del comercio minorista vallisoletano, 1750-1870", en TORRAS, Jaume y YUN, Bartolomé (Dirs.): Consumo, condiciones de vida y comercialización. Cataluña y Castilla, siglos XVII-XIX, Ávila, Junta de Castilla y León, 1999, pp. 355-376.

${ }^{36}$ MUÑOZ NAVARRO, Daniel: "Comercio de tejidos al por menor en la Valencia del siglo XVIII. Los Sumbiela y los Solernos. Dos linajes de botigueros de ropas", en Estudis, 34, 2008, pp. 285-302 y "Espacios de consumo en la Valencia preindustrial. Notas para una historia de la comercialización en la España Moderna", en MUÑOZ NAVARRO, Daniel (Ed.): Comprar, vender y consumir. Nuevas aportaciones a la bistoria del consumo en la España moderna, Sevilla, Universitat de València, 2011, pp. 99-120.

${ }^{37}$ MUI, Hoh.cheung y Lorna H.: Shops \& Shopkeeeping in eighteenth century England, Londres, Routledge, 1989.

${ }^{38}$ STOBART, Jon, HANN, Andrew y MORGAN, Victoria: Spaces of Consumption. Leisure and Shopping in the English Town, c. 1680-1830, Londres, Rotledge, 2007.

${ }^{39}$ NIETO SÁNCHEZ, José Antolín: "El acceso al trabajo corporativo en el Madrid del siglo XVIII: una propuesta de análisis de las cartas de examen gremial", Investigaciones de Historia Económica, 9, Madrid, 2013, pp. 97-107.

40 FRANCH BENAVENT, Ricardo, MUÑOZ NAVARRO, Daniel y ROSADO CALATAYUD, Luís: "La reproducción de los maestros y la transformación de las condiciones sociales de los miembros del Colegio del Arte Mayor de la seda de Valencia en el siglo XVIII", en Revista de Historia Industrial, 65, 2016, pp. 15-49.

41 SOLA PARERA, Angels y YAMAMICHI, Yoshiko: "Del aprendizaje a la maestría. El caso del gremio de velers de Barcelona, 1770-1834", en Áreas, 34, 2016, pp. 77-91.

${ }^{42}$ SANZ de la HIGUERA, Francisco: "'"han hallado hábil y suficiente en dho Ministerio...". Procesos de reclutamiento gremial en el Burgos del Setecientos", BIFG, 258, 2019, pp. 87-110.

${ }^{43}$ SOLA CORBACHO, Juan Carlos: "Capital y negocios: El comercio agremiado de Madrid a finales del siglo XVIII", Hispania, 204, 2000, pp. 225-253. 
Estas páginas se incardinan en el uso de documentos notariales y de actas municipales para la construcción de la historia económica, "lo que está estrechamente relacionado con el uso de las fuentes" ${ }^{4}$. Cipolla lo advirtió de forma genial cuando señaló que "el historiador reconstruye el pasado a partir de la documentación existente - con sus peculiaridades, con sus limitaciones, con sus lagunas y toda su riqueza -, a la que debe atenerse según unos criterios rigurosos": "En consecuencia, el historiador económico se ve obligado a adaptar sus preguntas a las fuentes de que dispone: dicho de otro modo, debe formular sus interrogantes teniendo en cuenta el período y la cultura que esté estudiando y los datos que se conservan" ${ }^{45}$.

\section{El devenir de tiendas y talleres en el Burgos del Setecientos}

Tanto la evolución de la población de la ciudad de Burgos - GRÁFICO I - como el devenir del dinero efectivo disponible en las talegas de los burgaleses ${ }^{46}$ - GRÁFICO II - y la constatación del número de tiendas urbanas - GRÁFICO III -, así como el seguimiento de la presencia en los hogares de múltiples enseres para la habitabilidad y la domesticidad, nos sugieren un patrón económico esencial al Setecientos. Parafraseando las excelentes palabras de Mantecón Movellán, en términos generales, "La cronología de los cambios en el gusto y en la preocupación de los compradores (...) muestra que es más que una revolución producida en el siglo XVIII lo que se experimentó, ya desde el XVII, fue un cambio que adoptó la forma de una evolución pausada, un efecto goteo en las direcciones apuntadas, acelerado, eso sí, en la segunda mitad del siglo XVIII y particularmente en las últimas tres décadas" ${ }^{47}$. Se produce "Crecimiento, pero más en la segunda mitad del siglo que en la primera"

Estas páginas, "Aclarando tintes demasiado oscuros" aproximación, dialéctica, a la economía urbana del Burgos del XVIII. En su diacronía, asoman momentos más efervescentes, y felices, con la apertura de tiendas y talleres artesanos, la disponibilidad de cosechas abundantes y precios asequibles. Pero también otros más siniestros, negativos y catastróficos - críticos -, en los que todos los parámetros se hunden en la miseria, la sequía, la inflación y la pérdida de expectativas empresariales.

${ }^{44}$ MORENO CLAVERÍAS, Belén: “CCómo se construye...”, pp. 1. Véase BELMONTE LÓPEZ, Mª Carmen, CUESTA MARTÍNEZ, Manuel, GARCÍA CANO, Mª Isabel y POZAS POVEDA, Lázaro: "Las actas capitulares como fuente para la historia urbana", En la España medieval, 10, 1984, pp. 156-181.

${ }^{45}$ CIPOLLA, Carlo: Entre la historia y la economía. Introducción a la bistoria económica, Barcelona, 1991, pp. 33.

${ }^{46}$ SANZ de la HIGUERA, Francisco: "Buena moneda y mala moneda en los hogares de Burgos en el siglo XVIII”, Pecunia, 16-17, 2013, pp. 13-40.

47 MANTECÓN MOVELLÁN, Tomás: op. cit., p. 237.

${ }^{48}$ LLOPIS, Enrique y AMARILLA, José Antonio: op. cit., p. 7.

${ }^{49}$ LLOPIS, Enrique y AMARILLA, José Antonio: op. cit. 

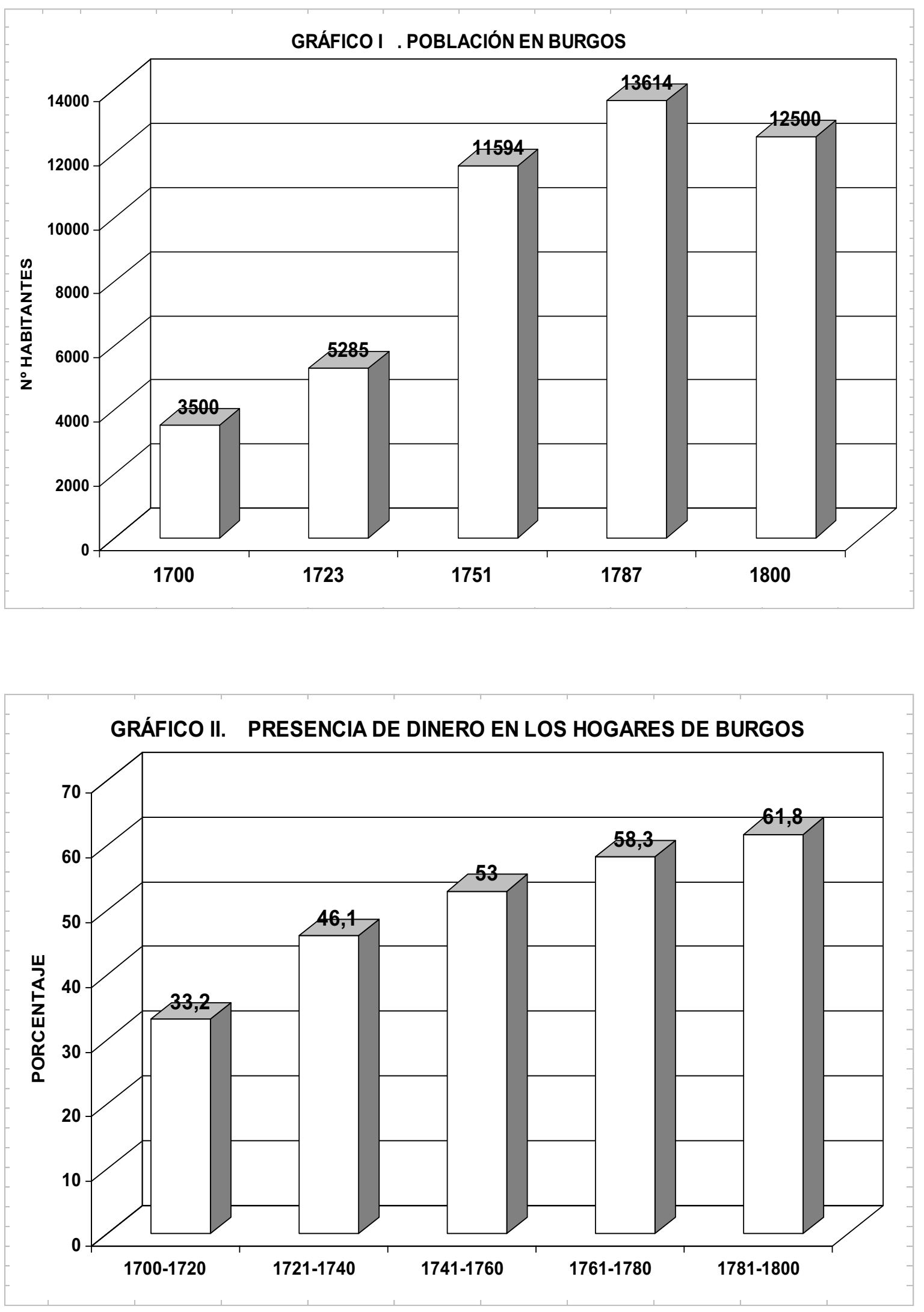

Fuente documental: AHPB. PN (1700-1800). Múltiples Legajos. 


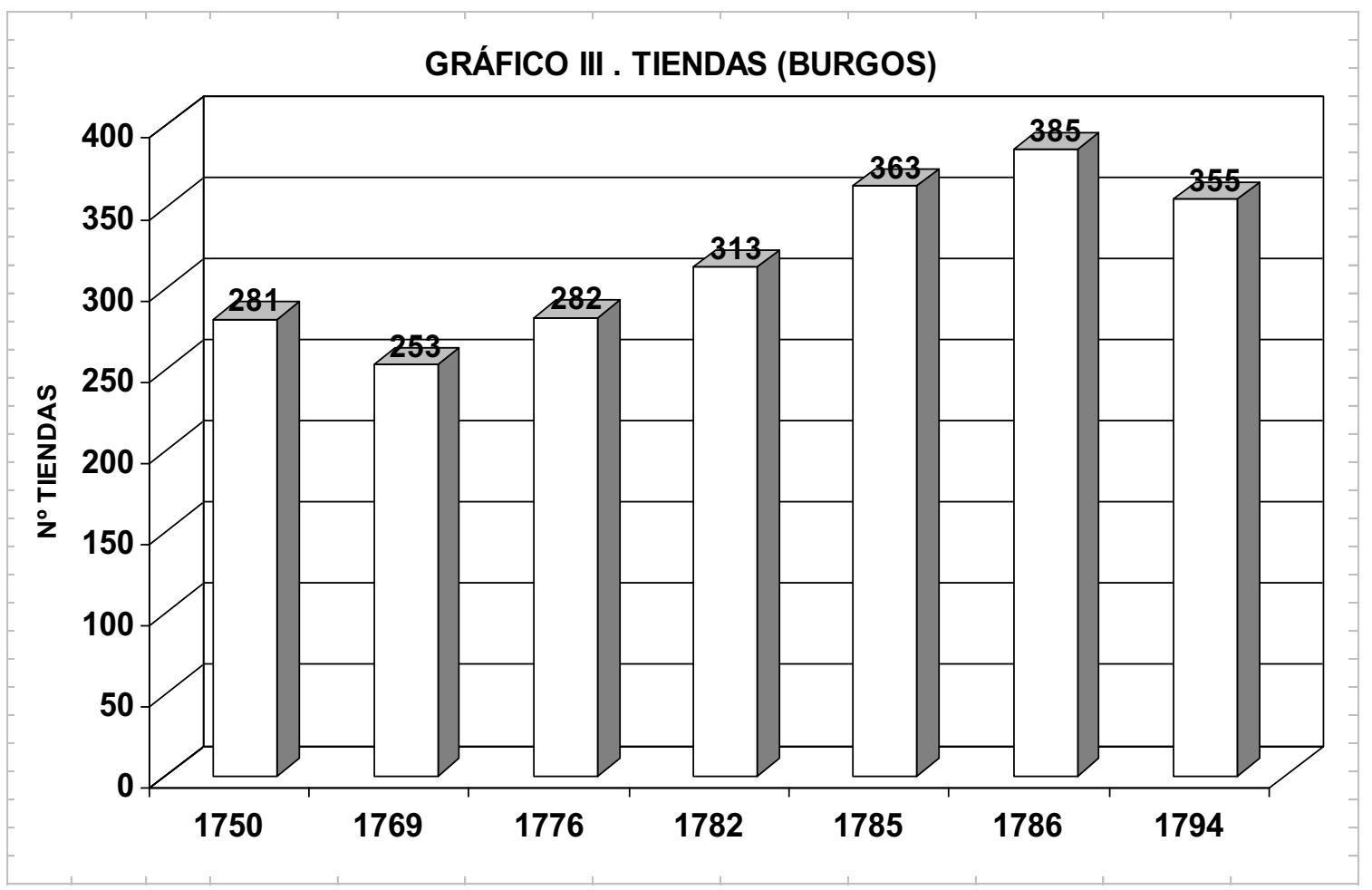

Fuente documental: Archivo Municipal de Burgos. Varias Carpetas ${ }^{50}$

El aserto generalizado se traduce en la percepción de una economía caracterizada por "un crecimiento limitado, sobre bases tradicionales" 51 . Una característica esencial de la economía castellana era el alto grado de autoconsumo dentro de unas estructuras muy compartimentadas. No se producía, ni en agricultura ni en industria, ni se comerciaba para un mercado nacional sino, más bien, en general, para un ámbito local o comarcal, a lo sumo. La decisión de radicar en el tejido urbano una "tienda" o un taller presuponía, además de la necesidad acuciante de ganarse la vida y mantener a la familia, la disponibilidad de un sitio concedido por el Concejo en función de las necesidades logísticas de la ciudad -. Se emitirán más o menos cartas de examen, y, por tanto, permiso para la instalación de nuevos maestros con taller, y se concederá licencia para la apertura de otras tiendas cuando se detecte su viabilidad y cuando la dialéctica oferta-consumo aconseje su idoneidad. Los pequeños "empresarios" que promovían la apertura de tiendas habían de contar con el visto bueno del

\footnotetext{
${ }^{50}$ Las visitas de tiendas en Archivo Municipal de Burgos. Carpeta 1-8-7 (1750), Carpeta 1-7-13/4 (1769), Carpeta C 1-7-13/4 (1775), Carpeta C 1-7-4/15 (1782, 1785 y 1786) y Carpeta C 2-10-9/15 (1794).

${ }^{51}$ HELGUERA QUIJANO, Juan: op. cit., pp. 56-92. Véase también CASADO ALONSO, Hilario: "Burgos según las Respuestas Generales del Catastro de Ensenada", en Burgos 1751: Según las Respuestas Generales del Catastro de Ensenada, Madrid, Tabapress, 1994, p. 39. Véase igualmente NIETO SÁNCHEZ, José Antolín y VELASCO MERINO, Eduardo: "Mercados de trabajo artesano en Castilla al final del Antiguo Régimen", en MELANG, James, ANDRÉS ROBLES, Fernando, BENITEZ SÁNCHEZ-BLANCO, Rafael, FRANCH BENAVENT, Ricardo y GALANTE, Miriam (Coord.), Palacios, plazas, patíbulos: la sociedad española moderna entre el cambio y las resistencias, Madrid, 2018, pp. 69-82.
} 
Concejo y de los gremios y tratos - en una estructura corporativa rígida y vertical - pero, sobre todo, con el pálpito de que iban a encontrar clientes, compradores, consumidores, para sus productos y quehaceres.

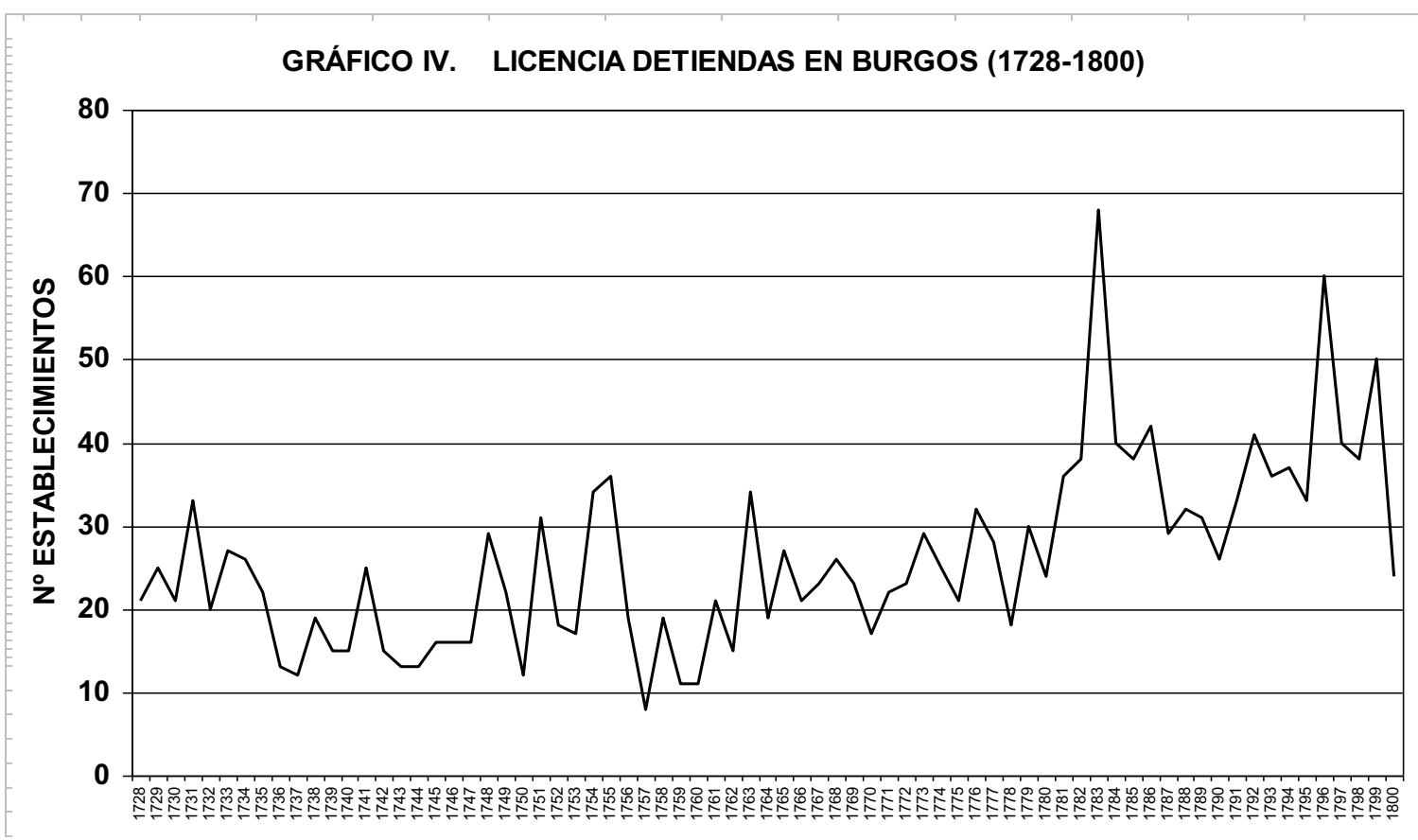

Fuente documental: Archivo Municipal de Burgos. Actas de Gobierno, de Abastos y Junta de Propios.

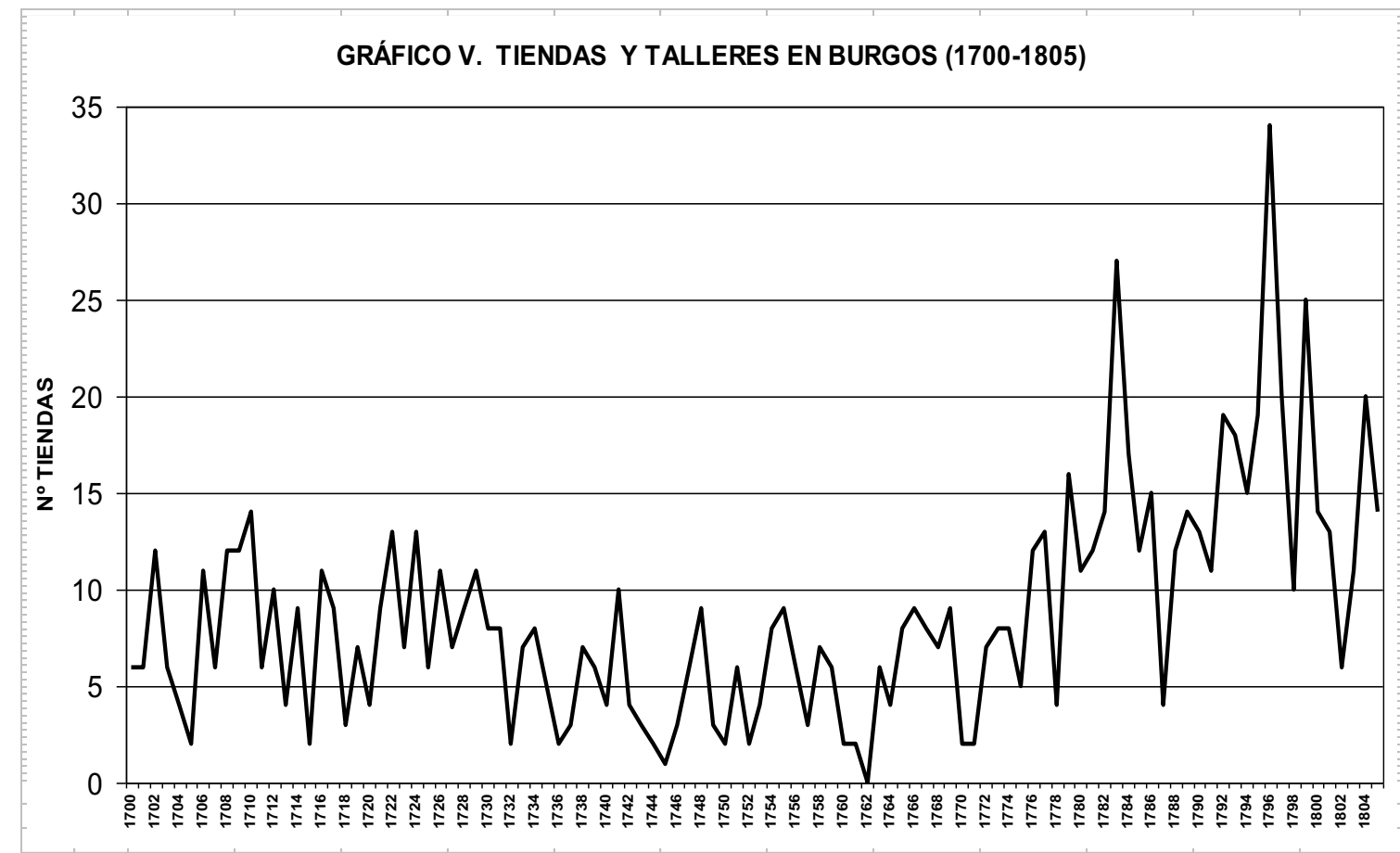

Fuente documental: Archivo Municipal de Burgos. Actas de Gobierno, de Abastos y Junta de Propios. 
Aunque se detectan algunas discrepancias, y disonancias, en la consideración de las tendencias visualizables en el devenir de tiendas, ya sea sin los talleres artesanos - GRÁFICO IV - como en su versión mixta, es decir, tiendas más talleres - GRÁFICO V -, cartas de examen - GRÁFICO VI - y producción de trigo - GRÁFICO VII -, desde una perspectiva global se produjeron, a mi juicio, en la diacronía secular, tres grandes momentos bien caracterizados. En primera instancia, el segmento temporal 1700-1736. En segundo término, la etapa 1736-1779 y, a la postre, el último período secular, entre 1779 y 1800. Cada una de ellas está sujeta a fenómenos zigzagueantes, los dientes-de-sierra usuales en cualquier fenómeno económico de evolución. Empero, las vicisitudes generales que se entreven en cada tramo están enraizadas en una idiosincrasia similar.

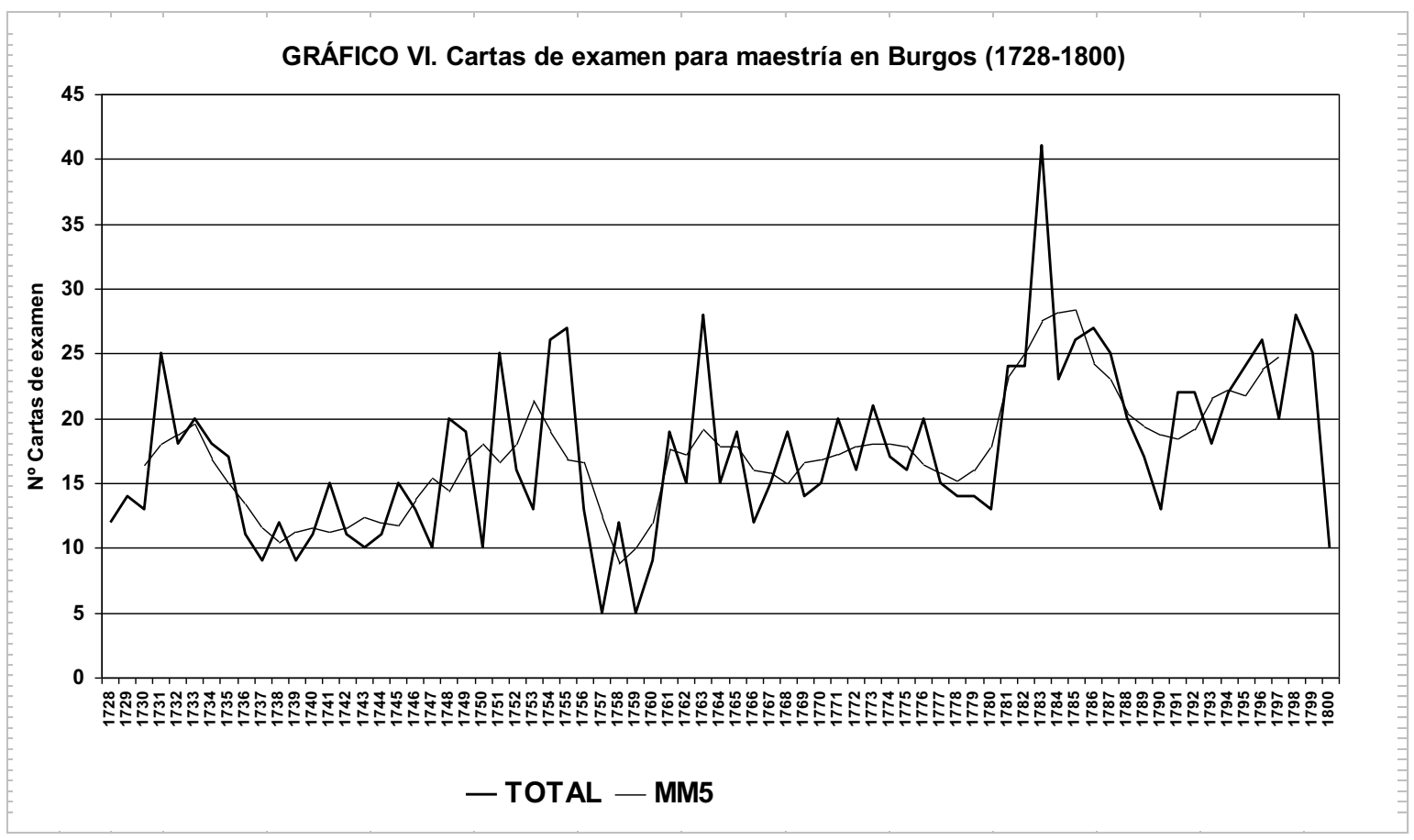

Fuente documental: AHPB. Concejil. Múltiples Legajos y AMB. Múltiples Carpetas.

\subsection{Las “taquicardias" de 1700-1736.}

En este segmento temporal, el primer tercio de siglo bajo la nueva dinastía borbónica, se aprecian, tanto desde la perspectiva de las de tiendas como desde la óptica de la producción agraria, un devenir bastante espasmódico - GRÁFICO IV y GRÁFICO VII -. Un primer estadio, 1700-1705, dubitativo. Una segunda etapa, 1706-1710, de cierto, aunque precario, crecimiento. Un tercer tramo, 1711-1718, de notable crisis. Un cuarto segmento, 1719-1724, de nueva expansión y, a la postre, la fase 1725-1736 marcada, de nuevo, por la intranquilidad. 


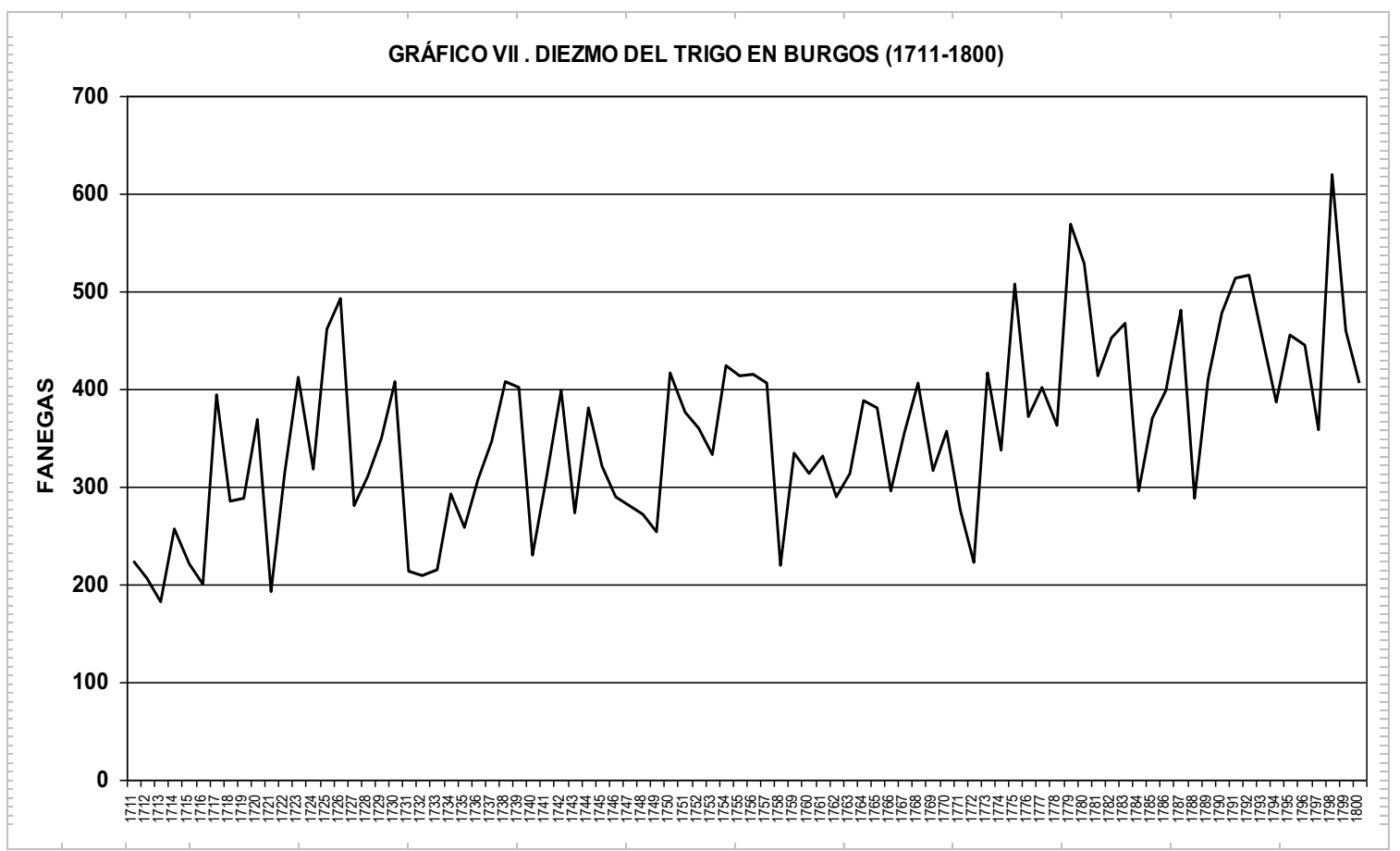

Fuente documental. Archivo Diocesano de Burgos. Libros de tazmías de San Martín, San Gil, San Román, San Cosme, San Esteban, Viejarrúa y Cortes.

1700-1705 abrió la puerta al Setecientos con un sube y baja en las licencias de tiendas bastante intenso, acorde a las inciertas expectativas generadas por la guerra de sucesión y la llegada de la nueva dinastía. Era un momento de incertidumbre, con un 1701 caracterizado por un "dilatado Yvierno" 52 . 1706-1710 supuso un notable incremento en las licencias de tiendas. En 1706 se amplió el número de consumidores de manera significativa, porque "aviendose establezido aqui la Corte Y Concurrido a Abitar En ella el numero y Gran Concursso de Jente que es notorio", se precisaban más tiendas y talleres para satisfacer sus demandas. Disfrutaban de "Sobrada niebe" y "En expezial en este tiempo Presente [julio] de tan Eszesibos Calores"53. El matiz negativo era la "gran secura que se Ba experimentando" 54 , lo que generaba la "gran falta de Aguas que tienen los Campos, Con atraso de sus frutos" ${ }^{55}$, circunstancia perjudicial no sólo para la labranza y la capacidad de consumo. Había más población y demanda, se precisaba más

\footnotetext{
52 AMB. AG. Regimiento ordinario (RO) del 14 de abril de 1701, folios 141v-142r. En ningún momento se va a mantener una relación preeminente del clima sobre la economía. Sí una influencia significativa, aunque ni inopinadamente vinculante ni jerárquicamente dominante. Comparto las reflexiones de MARCOS MARTÍN, Alberto: op. cit., pp. 15-17, GARCÍA SANZ, Ángel: op. cit., pp. 23-27 y, por supuesto, ALBEROLA ROMÁ, Armando: Catástrofe, economía y política en la Valencia del siglo XVIII, Valencia, Institució Alfons el Magnànim, 1999. Un clima adverso infiere problemáticas dramáticas a la economía en general y a la micro-economía urbana en particular, pero no la determinan de manera irremediable.

53 AMB. AG. RO del 16 de julio de 1706, 183v-184r.

54 AMB. AG. RO del 15 de abril de 1706, 86r-87v.

55 AMB. AG. RO del 22 de mayo de 1706, 124v-125r.
} 
oferta - se abrían tiendas - pero las sacas de grano para los ejércitos ${ }^{56}$ y la climatología enturbiaban el panorama. Era un clamor general, "con el motivo de la Corta Cosecha de frutos que a avido enella" 57 . La "falta de granos" pasaba factura y no ocultaba la "gravedad del negocio y ponderando en ella la estrechez en que esta Ciudad se halla" ${ }^{58}$. El mayordomo del pósito ${ }^{59}$ denunciaba la falta de trigo y comuña "por haver sido la Cosecha en aquella Tierra mui corta, que está temblando le falte $p^{a}$ el consumo y abasto de aquella Ciudad"60. En enero de 1710 hubo "mucho Yelo y nieve" y persistían las angustias "por la suma falta de granos que ay" ${ }^{62}$. Una flagrante contradicción aquejaba a la población, obligada a enjugar sus lágrimas, llevando a cabo, simultáneamente, "Rogativas sobre la Serenidad deel tiempo por las muchas Aguas que se experimentan", y lamentando la "Escasez, de granos (...) ha causa de las grandes necessidades que están padeciendo los Pueblos de esta Comarca" ${ }^{63}$. A ello se unían las quejas de los "empresarios" por el excesivo volumen de impuestos que pagaban ${ }^{64}$.

1711-1718 supuso un grave bache en la apertura de tiendas y en los rendimientos agrícolas, fiel reflejo de los desperfectos de los dos años anteriores y de los que habrían de venir. Los tenderos se quedaban de "la carestía que en todos jeneros se experimenta", en especial, el "encarecido Prezio de la Zebada" y " "la tiranía de las Panaderas de Arcos porque suben el Prezio deel Pan Cozido a su Voluntad" ". Se denunciaba "el gran consumo que ay de dho Carbon"68, por el mucho frío reinante en esos años - "es notorio y General el mal temporal que a echo en el Yvierno de aguas y niebes, Motivo para que todos los frutos se hayan y esten atrasados y [gran] mortandad de Ganado de

\footnotetext{
${ }_{56}$ Así, por ejemplo, se canalizaron 20.000 fanegas de cebada para el ejército. AMB. AG. RO del 19 de enero de 1709, folio 49r.

57 AMB. AG. RO del 1 de octubre de 1708, 284rv.

58 AMB. AG. 3 de octubre de 1709, 327v-328r.

59 SANZ de la HIGUERA, Francisco: “Cultura material de los mayordomos del pósito y "lóndiga” en el Burgos del Setecientos”, BIFG, 257, 2018, pp. 307-325.

${ }^{60}$ AMB. AG. RO de 3 de octubre de 1709, 331v. Véanse, entre otras, las propuestas de EIRAS ROEL, Antonio: "Hambre y peste en Santiago en 1710", Cuadernos de Estudios Gallegos, 61, 1965, pp. 243-255; GUTIÉRREZ NÚÑEZ, Francisco Javier y GARCÍA BERNAL, José Jaime: "La crisis de 1708-1709 en Sevilla a la luz de la nueva documentación (II). Las certificaciones parroquiales", en Congreso Internacional de Andalucía Barroca, Antequera, Junta de Andalucía, 2007, pp. 269-277 y FERNÁNDEZ CORTIZO, Camilo: “¿En Galicia, el hambre entra nadando? Rogativas, clima y crisis de subsistencias en la Galicia litoral sudoccidental en los siglos XVI-XVIII", Semata, 17, 2005, pp. 259-298.

61 AMB. AG. RO del 11 de enero de1710, 15r.

62 AMB. AG. RO del 24 de marzo de 1710, 77r.

${ }^{63}$ Citas textuales en AMB. AG. RO del 12 de junio de1710, 119v-120v. Resultan imprescindibles ALBEROLA ROMÁ, Armando: Los cambios climáticos. La Pequeña Edad del Hielo en España, Madrid, 2014 y Quan la pluja no sap ploure. Sequeres i riuades al País Valencià en l'edat moderna, Valencia, Universitat de València, 2010.

${ }^{64}$ AMB. AG. RO del 31 de julio de 1710, folios 175r-176v. La guerra demandaba dinero y el Rey exigía donativos "con la mayor cantidad que fuere posible". AMB. AG. RO del 25 de septiembre de 1710, 242r.

65 AMB. AG. RO del 12 de enero de 1711, 23v.

66 AMB. AG. RO del 15 de junio de 1715, 162v.

${ }^{67}$ AMB. AG. RO del 1 de junio de 1715, 144v-145r.

68 AMB. AG. RO del 12 de noviembre de 1712, 236v.
} 
Bueyes y Carneros" - Se imponían las rogativas por "la gran falta de agua que se Experimentaba" en 1715-1716 y 171870. La "Ynjuria de los tiempos" ${ }^{71}$ mermaba los ingresos de la población, sobre todo de los aristócratas rentistas, clérigos, labradores y artesanos, y ralentizaba el consumo y la apertura de tiendas. Un ejemplo impactante lo encontramos en las palabras de un maestro confitero que advierte que "oy, a Causa de la Ynjuria de los tiempos y Suma falta de medios, a llegado el caso de sser tan corto el consumo y gasto, siendome preciso, para el Surtimiento de la tienda, Comprar Cada Semana"72. La gran sequía de la época provoca una "Corta Cosecha" continuada, de modo que "no se ha cogido ni para pagar la Renta"73.

1719-1724 fue un período más benigno, con un significativo crecimiento en la apertura de tienda y en la mejoría de las cosechas. Apenas se enfatiza la carencia de agua, se indica la presencia de "Grandes Calores (...) [y], mucho consumo" de nieve en las alojerías", si bien a partir de 1723 se vuelve a la tónica de la sequía, que se agrava a partir de 1724 "por la Urgencia de la falta de Aguas" ${ }^{35}$. Las cosechas eran irregulares y de mala calidad, y había problemas con las bebidas frías " a Causa de haver nevado tan poco en esta Ciudad, y la blandura que se siguió Inmediatamente (...) [que se recogió] mui poco en la nevera" ${ }^{276}$. Empero a finales de 1724, un manto blanco cubrió las calles, "respecto de la mucha [nieve] que abia Caido"77.

1725-1736 trajo, de nuevo, sombrías perspectivas a la economía urbana. La apertura de tiendas se reduce de manera notable, las cosechas no acompañaban y la reducción en el volumen de las cartas de examen delatan que el mercado industrial no precisaba de nuevos talleres, como consecuencia de las mermas económicas y la falta de de consumo. Los maestros de obra prima - léase zapateros - se quejaban, amargamente, de que había quedado "reducido el trato, por la miseria de los tiempos, a solo doze maestros" ${ }^{78}$. Las "Calamidades de los tiempos" retornaron con la "falta de aguas", lo que obligó a la realización de rogativas en 1726 79 . La letanía de "baver sido La Cosecha de Mala Calidad", ser "Corta la Cosecha de este año"81 y del "temporal riguroso de aquella estación", dejando las calles y las plazas "llenas de lodos", preñaba,

${ }^{69}$ AMB. AG. RO del 4 de mayo de 1713, 141r-142v.

70 AMB. AG. RO del 21 de mayo de 1715, 130v-131r, 5 de octubre de 1715, 263r y 7 de mayo de 1716, 91v-92r, 5 de septiembre de $1718,244 \mathrm{rv}$.

71 AMB. AG. RO del 8 de agosto de1716, 179r.

72 AMB. AG. RO del 2 de junio de 1718, 143v-144r.

73 AMB. AG. RO del 24 de octubre de 1718, 280v-281r.

74 AMB. AG. RO del 31 de agosto de 1722, 250v-251r.

75 AMB. AG. RO del 27 de mayo de 1724, 158v.

76 AMB. AG. RO del 26 de agosto de 1724, 262r.

77 AMB. AG. RO del 2 de diciembre de 1724, 379r.

78 AMB. AG. RO del 24 de noviembre de 1725, 231v.

79 AMB. AG. RO del 16 de noviembre de 1726, 288v.

80 AMB. AG. RO del 20 de octubre de 1727, 273rv.

${ }^{81}$ AMB. AG. RO del 17 de noviembre de 1727, 296r.

82 AMB. AG. RO del 20 de noviembre de 1727, 300v-301r. 
de nuevo, los sinsabores de la ciudad pre-industrial. La meteorología perseguía, siempre inmisericorde, por defecto o por exceso, a la economía urbana. Por ejemplo, como consecuencia del "accidente de gran temporal de Nieve (...), que en dos meses y más no pasó Persona alguna, y por haver faltado la Casa Real de Madrid ba avido y ay menos Comercio"83, con grave de deterioro del consumo y de las expectativas de talleres artesanos y tiendas en general. Fueron momentos difíciles "por los muchos yelos en últimos del año 1728 y principios de 1729" 84 . El pósito se veía obligado a repartir miles de fanegas de trigo "respecto de la Cortisima Cosecha que en este año an tenido" en 1731-1735 " "baviendose experimentado la aflicción y desconsuelo por la falta de trigo y demás Xeneros de esta clase" ${ }^{\prime \prime 6}$.

\subsection{El escaso dinamismo de 1737-1778.}

Este largo período se puede segmentar en tres tramos, cada uno de los cuales presenta unas características más o menos homogéneas. Múltiples oportunidades llamaban a las puertas de la economía, dado que "un conjunto de presiones (...) estaba propiciando que, vía intensificación del uso de la mano de obra disponible, elevasen sus niveles de actividad económica, y la expansión de los mercados aportó un estímulo añadido"87. En primera instancia, 1737-1755, en el que se advierte un moderado crecimiento no exento de problemas. En segundo término, 1756-1760, marcado por una profunda crisis y, a la postre, 1761-1778, definido por la atonía y puntuales situaciones explosivas, como la revuelta contra Esquilache (1766).

1737-1755 es una etapa, controvertida, en la que nos topamos con un notable crecimiento de la expedición de cartas de examen. Los gremios urbanos se encontraban en una fase efervescente, prueba diagnóstica de que sus negocios, y la necesidad de ampliar las cuotas de drenaje del gasto privado, y público, no estaban excesivamente deprimidos. Empero, las tiendas, sin considerar en su seno ahora los talleres artesanos, discurrieron por la senda de la precariedad, con una capacidad de apertura de locales y garitos muy reducida. La climatología, y, por tanto, la producción agraria, tuvo, en general, un comportamiento aceptable, no exento de incómodas recaídas - por ejemplo, 1745-1749 -. El tendero Bernardo Gutiérrez, a través de su memorial para el Catastro de Ensenada, expuso lo que

\footnotetext{
83 AMB. AG, RO del 23 de marzo de 1730, 112v-113r.

84 AMB. AG. RO del 23 de octubre de 1730, 280rv.

85 AMB. AG. RO del 24 de noviembre de 1731, 272v, del 29 de noviembre de 1732, 243v, del 28 de septiembre de 1733, 178v, del 21 de agosto de 1734, 185r y del 27 de enero de 1735, 37rv.

86 AMB. AG. RO del 27 de noviembre de 1734, 237r.

${ }^{87}$ LLOPIS, Enrique y AMARILLA, José Antonio: op. cit., p. 32.
} 
probablemente muchos sentían, y pensaban. La época que les tocaba vivir, y sufrir, estaba preñada de notables problemáticas, "con el motibo de tantas tiendas y benderse poco" ${ }^{8}$. El mercader de paños y sedas Gregorio Bernáldez de Velasco ${ }^{89}$ lo corroboraba, a su manera, al afirmar que se encontraban instalados en un "estancamiento comercial" generalizado".

Un problema añadido era, siempre, la inflación. Un maestro fontanero se atrevía a sentenciar que "de alimentos todo está mui caro" ". La meteorología persistía en su denodado afán por crear sinsabores. En 1737-1738, hubo quejas por los excesivos calores ${ }^{92}$ pero también "por no haver llovido ni nevado en este Invierno", circunstancias que enervaban a los labradores, impedía las moliendas, incrementaba los precios y restaba ingresos a los artesanos y tenderos. La irregularidad de las precipitaciones sorprendía a unos y otros. Así, por ejemplo, en diciembre de 1739, se dejaba atrás la sequía "a causa de las Continuadas Lluvias que se experimentan y aumento que cada día toman los Rios [de modo que] se puede Recelar xustamente crecidas grandes que imposibiliten el uso de los molinos"94. Al inicio del año siguiente, "con el motivo de la mucha nieve y Yelos que a caido y se experimentan" era preciso "habrir los Caminos zerrados absolutamente por la mucha nieve" ${ }^{95}$, los tránsitos de personas, mercancías y animales se colapsaron. Con todo, valga la ironía, los responsables del pósito denunciaron "la Corta Cosecha deste año",96 lo que desató el clamor endémico de los labradores, que exponían, de manera constante, "les es imposible de poder Sembrar sino se les da trigo prestado de la londiga" ${ }^{97}$. La precariedad de los campos anunciaba dificultades en los talleres artesanos y en las tiendas en general, tanto por la escasez de demanda de los más acaudalados como de los menos afortunados. Las malas cosechas congelaban los flujos comerciales, como el frío entumecía las ciudades, "a causa de haver sido el Ynvierno en este país sumamente riguroso" ${ }^{98}$.

\footnotetext{
88 Archivo de la Diputación Provincial de Burgos (ADPB). Catastro de Ensenada (CE). Respuestas Particulares. Libro 344, folio 421r.

${ }^{89}$ SANZ de la HIGUERA, Francisco: "Perspectivas de negocio y cultura material en una saga de comerciantes burgaleses del XVIII. Los Bernáldez de Velasco", BIFG, 255, 2017, pp. 361-384.

90 ADPB. CE. RP. Libro 345, folio 22.

91 AMB. AG. RO del 2 de diciembre de 1737, 275v.

92 AMB. AG. RO del 2 de diciembre de 1737, 276r y del 10 se septiembre de 1738, folio 242v.

93 AMB. AG. RO del 10 de mayo de 1738, 133v.

94 AMB. AG. RO del 5 de diciembre de 1739, 356r.

95 AMB. AG. RO del 1 de febrero de 1740, 43r. Véanse ALBEROLA ROMÁ, Armando: “"No puedo sujetar la pluma de puro frío, porque son extremados los yelos": El clima en la España de los reinados de Felipe V y Fernando VI a través de la correspondencia de algunos ilustrados", Investigaciones Geográficas, 49, 2009, pp. 65-88 y "Los problemas de primavera y verano en la agricultura. Notas acerca de granizos y heladas en tierras valencianas durante el siglo XVIII", Pedralbes, 26, 2006, pp. 11-40.

96 AMB. AG. RO del 3 de octubre de 1740, 286r.

97 AMB. AG. RO del 27 de noviembre de 1741, 399v-400r.

98 AMB. AG. RO del 13 de mayo de 1743, 117rv.
} 
Los años pasaban y, de manera severa, los artesanos y comerciantes denunciaban la "la Calamidad de los tiempos, por la falta del trato de comercio en esta Ciudad", aguijoneados por la "presión de pagar Crecidas Sumas de mrs por contribuciones reales a S.M." y "Satisfacer subidas Cantidades por las Casas de nra babitación"". Otra vez hubo de recurrirse a las rogativas porque "se necesitan buenos temporales" ${ }^{100}$, aunque muchos labradores exponían su perplejidad ante el hecho contradictorio de que "por la mucha Continuación de aguas que havido en el Agosto deeste presente año no an cogido trigo seco que poder Sembrar" ${ }^{101}$. En 1748, "en atención haver sido mui Corta la Cosecha"102 retornaban las carencias, compartidas por la economía del Ayuntamiento, dado que "se le bacia annualmente hera sumamente grabosa por el ynfeliz. Estado y escasez. en que se allan sus Propios, motivando la Ymposibilidad de la Satisfacción de dhos gastos" ${ }^{103}$. El sentimiento de postración era generalizado, "con el motibo de la pobreza a que ha quedado reducido en los Vecinos desta Ciudad"104. La inyección de individuos, en "mucho número", que trajo consigo la llegada del Regimiento de Inválidos de Cataluña en $1750^{105}$ dinamizaba las posibilidades de incremento del consumo, pero también generaba graves patologías a los vecinos de la ciudad, en especial por "la falta que el Pueblo experimentava de Carbon, huebos y otros Comestibles" ${ }^{106}$. La marcha del Regimiento de Inválidos a Zamora truncó los florecientes consumos de vinos en las tabernas, en el aguardiente, en las tiendas, en las panaderías, en el estanco del tabaco - "respecto el poco consumo por la falta de los soldados" ${ }^{107}$.

1756-1760 aparece, en el devenir del Setecientos urbano burgalés, como un profundo bache crítico en el que se desploman la emisión de cartas de examen - GRÁFICO VI -, la solicitud de licencias para la apertura de tiendas - GRÁFICO IV - y la producción de cereales, en especial de trigo - GRÁFICO VII -. Los años más castigados fueron 1758 y 1759. En febrero de 1758, debido "a lo riguroso del temporal" el Cabildo Catedral y el Concejo determinaron la celebración de una rogativa para que "se dignase mitigar su rigory aplacar el tiempo, mejorandole" $"$. Gran parte de la cosecha se malogró "a causa deel Nublado y Creziida Abundancia

\footnotetext{
99 AMB. AG. RO del 15 de junio de 1747, 108v-109r.

100 AMB. AG. RO del 2 de octubre de 1747, 239rv.

101 AMB. AG. RO del 18 de noviembre de 1747, 288r.

102 AMB. AG. RO del 26 de octubre de 1748, 376rv.

103 AMB. AG. RO del 14 de octubre de 1748, 366r.

104 AMB. AG. RO del 30 de octubre de 1749, 281v-282r.

105 SANZ de la HIGUERA, Francisco: "Alojamiento de tropas en Burgos a mediados del siglo XVIII. Cuarteles, alquileres y hospitales para el Regimiento de Inválidos de Cataluña (1748-1753)", en Milicia y sociedad ilustrada en España y América (1750-1800), Madrid, Cátedra "General Castaños", 2003, tomo I, pp. 335-360 y BORREGUERO BELTRÁN, Cristina: "Alojamiento de tropas e incremento del comercio en Burgos en la época Moderna”, en PEÑA PÉREZ, Francisco Javier y PAYO HERNÁNZ, René Jesús (Coords.): op. cit., pp. 213-229.

106 AMB. AG. RO del 23 de noviembre de 1750, 233-238.

107 AMB. AG. RO del 3 de marzo de $1755,47 \mathrm{v}-48 \mathrm{r}$.

108 AMB. AG. RO del 2 de febrero de 1758, 48r.
} 
de Piedra que Caio en esta Ciudad en el mes de junio, haviendole maltratado y dejado arruinados totalmente los Sembrados (...) de tal forma que aún no ha[n] Cojido lo Correspondiente para poder Sembrar ${ }^{\prime 109}$. En 1759, la ciudad se vio azotada por las consecuencias de la "Esterilidad de frutos" de la cosecha frustrada ${ }^{110}$, circunstancia lamentable que también alcanzó a 1760, por la "Corta Cosecha" de turno ${ }^{111}$. No era necesario reemplazar a los maestros fallecidos porque apenas había negocio y prácticamente nadie se atrevía a abrir tiendas por la falta de expectativas de consumo.

En 1761-1778 persistió la atonía, dubitativa. Las posibilidades de que el entramado urbano mejorara substancialmente sus capacidades de consumo eran escasas. Aunque en 1763 nos topamos con un potente volumen de cartas de examen, únicamente fue un espejismo puntual en una anquilosada horizontalidad persistente. Lo cierto es que las tensiones habituales estrangulaban la oferta y la demanda. Se lamentaban los tenderos y artesanos del descenso en la "Venta de géneros", no sólo de los comestibles, "respecto haverse suvido el precio de ellos" ${ }^{112}$, y ser manifiesta la inflación en los alquileres ${ }^{113}$. Las economías campesinas también se encontraban maltrechas, hasta el punto de "que [era] imposible Satisfacer [las rentas y la devolución de los préstamos] a Causa de la Corta Cosecha (...) no sólo en el año presente sino en las anteriores, Como es notorio, por lo Calamitoso de los tiempos" ${ }^{114}$. Poca efervescencia se podía esperar dado el "infeliz estado en que se halla esta Ciudad"115, acuciada por los "muchos Pobres que bay" ${ }^{116}$. El desabastecimiento era notorio y "ha dos años con Corta diferencia (...) en que se ha experimentado grande pérdida" por las actuales guerras ${ }^{117}$. La paz con Inglaterra y con Portugal fueron muy positivas, "quedando restablecido y avilitado el comercio"

En 1764, se consolida la tendencia, dañina, de la especulación y la manipulación de precios. Se pensaba "que haviendo Sido generalmente la Cosecha de Granos más que mediana en todas las Provincias se moderasen los precios de su Venta, Como Combiene al Común" pero, en la práctica, la realidad es otra. Y hasta el Rey se lamentaba "con mucho Sentimiento [de] que se Conserban los precios altos que havia antes de la Cosecha por guardarse los Granos sin vender hasta que Suban los precios a la altura que dicta a sus Dueños la Codicia" ${ }^{119}$. Cuando confluyen "lo riguroso deel tiempo (...) [con]

\footnotetext{
109 AMB. AG. RO del 5 de octubre de 1758, 278v.

110 AMB. AG. RO del 15 de enero de 1759, 26r.

111 AMB. AG. RO del 27 de noviembre de 1760, 308r.

112 AMB. AG. RO del 13 de septiembre de 1762, 140r.

113 SANZ de la HIGUERA, Francisco: "La vivienda en el Burgos del Setecientos. Inflación en los alquileres, escasez en los bolsillos", en BIRRIEL SALCEDO, Margarita (Ed.): La(a) casa(s) en la Edad Moderna, Zaragoza, Institución "Fernando el Católico", 2017, pp. 428-469.

114 AMB. AG. RO del 7 de octubre de 1762, 145r.

115 AMB. AG. RO del 24 de marzo de 1763, 58-60.

116 AMB. AG. RO del 10 de marzo de 1763, 46r.

117 AMB. AG. RO del 18 de noviembre de 1762, 156v-157r.

118 AMB. AG. RO del 24 de marzo de 1763, 61v-62r.

119 AMB. AG. RO del 27 de agosto de 1764, 93r.
} 
muchas Niebes" ${ }^{120}$, con los precios disparados, las malas cosechas ${ }^{121}$ y los pésimos temporales ${ }^{122}$, la conmoción pública está garantizada ${ }^{123}$. En 1769, retornan, y va a ser un fenómeno endémico, el pedrisco y la cortedad de las cosechas. Múltiples labradores denunciaron que "por haverse apedreado el año pasado proximo sus frutos y sembrados, y que al presente es tan estéril y tan Corta [la] Cosecha que se hallan con grande infertilidad, imposible de poderlas sembrar" ${ }^{24}$. Las pérdidas de los campesinos mermaban, aunque fuera en poco, las ventas de los talleres artesanos y de las tiendas en general. A pesar de todo, Burgos era atractivo. Y así, por ejemplo, Carlos José Bosi y su compañero Roberty, posaderos en los Reales Sitios, se arriesgaron a "poner una Posada de Cavalleros y Pasajeros con Café y Mesa redonda en la Ciudad de Burgos, con la mayor limpieza y aseo, (...) considerando ser mui util asi para todo genero de Pasagero como para los Vecinos de dha Ciudad, y también para la tropa de S.M." ${ }^{125}$. En 1768, Pedro Bourdet y Francisco Huvert, franceses, tomaron en la Plaza Mayor una casa "con la idea de establecer un Café decente para servicio pp"y ynas de trucos y de Billar para su honesto entretenimiento"126.

La oscilación Maldà, caracterizada por la ocurrencia de fenómenos de elevada variabilidad catastrófica ${ }^{127}$, se percibe en Burgos ya desde 1775, y va a afectar, poco después, también, a la creación de talleres artesanos, a la apertura de tiendas y a la producción agraria. En mayo de 1775, se efectuaban rogativas por la "gran necesidad de agua"128 y, meses después, se producía una tremenda "Avenida", es decir, una aparatosa inundación que asolaba la ciudad" ${ }^{129}$. "La espantosa Crecida de Agua" precisó inversiones por valor de 299.140 reales ${ }^{130}$. Para no ser menos, en febrero de 1776, retorna el mal ambiente, con rogativas "por mal temporal de Nieves y lluvias" excesivas ${ }^{131}$. De la inmensa mayoría de las tiendas y talleres surge un clamor angustioso por la "decadencia que se experimenta en sus respectivos gremios por la Corta Venta de sus géneros". En concreto, los mercaderes de paños y sedas señalaban que "se balla este

\footnotetext{
120 AMB. AG. RO del 13 de febrero de 1766, 26r.

${ }^{121}$ AMB. AG. RO del 25 de agosto de 1766, 206v. "en atención a los Ynformes que avia formado de que la presente Cosecha de este pays hera muy Corta".

122 AMB. AG. RO del 26 de mayo de 1766, 91v.

123 Véanse, por ejemplo, las contribuciones de ANES GONZALO, Gonzalo: “Antecedentes próximos del motín contra Esquilache”, Moneda y Crédito, 128, 1974, pp. 219-224; EGIDO, Teófanes: "Madrid 1766: "Motines de Corte" y oposición al gobierno", Cuadernos de Investigación Histórica, 3, 1979, pp. 125-153; VILAR, Pierre: "El "motín de Esquilache" y las "crisis del antiguo régimen", Revista de Occidente, 107, 1972, pp. 199-249 y RODRÍGUEZ, Laura: "Los motines de 1766 en provincias”, Revista de Occidente, 122, 1973, pp. 183-207.

124 AMB. AG. RO del 6 de noviembre de $1769,326 \mathrm{v}-27 \mathrm{r}$.

125 AMB. AG. RO del 22 de diciembre de 1766, 309rv.

126 AMB. AG. RO del 2 de febrero de 1768, 65r.

127 BARRIENDOS, Mariano y LLASAT, Carmen: "The case of the "Maldá" anomaly in the Western mediterranean basin (AD 1760-1800): an example of a strong climatic variability", Climatic Change, 61, 2003, pp. 191-216.

128 AMB. AG. RO del 20 de mayo de 1775, 77r-78r.

${ }^{129}$ AMB. AG. RO del 1 de agosto de 1775, 94v-95r y JPA. RO del 9 de enero de 1776, 12 r.

${ }^{130}$ AMB. JPA. CO del 9 de enero de 1776, 12rv.

131 AMB. AG. RO del 12 de febrero de 1776, 39v-40r.
} 
Comercio en la maior decadencia por la variedad de los tiempos". Los "Yndividuos del trato de Obra prima" eran, incluso, más sardónicos, al denunciar "ballarse en el estado más miserable y decadencia por la corta venta de Zapatos que les ha constituido cuasi en la Ymposivilidad de corresponder a la paga de tributos reales y manutención escasa de su Casa y familia" ${ }^{132}$. El enorme lastre fiscal atenazaba a gran parte de la población, pero en especial a los comerciantes, tenderos y artesanos, además de "ser imposible a los Pobres Suplicantes hacer otro pagamiento por el miserable estado en que se ballan, motivado del infortunio de los tiempos que han acaecido, como es notorio"133. A pesar de todo, Burgos era una ciudad atractiva para muchos empresarios, como, por ejemplo, Sebastián Steiner, "de Nación Alemán”, y su fábrica de jabón ${ }^{134}$.

\section{La engañosa efervescencia de 1779-1800.}

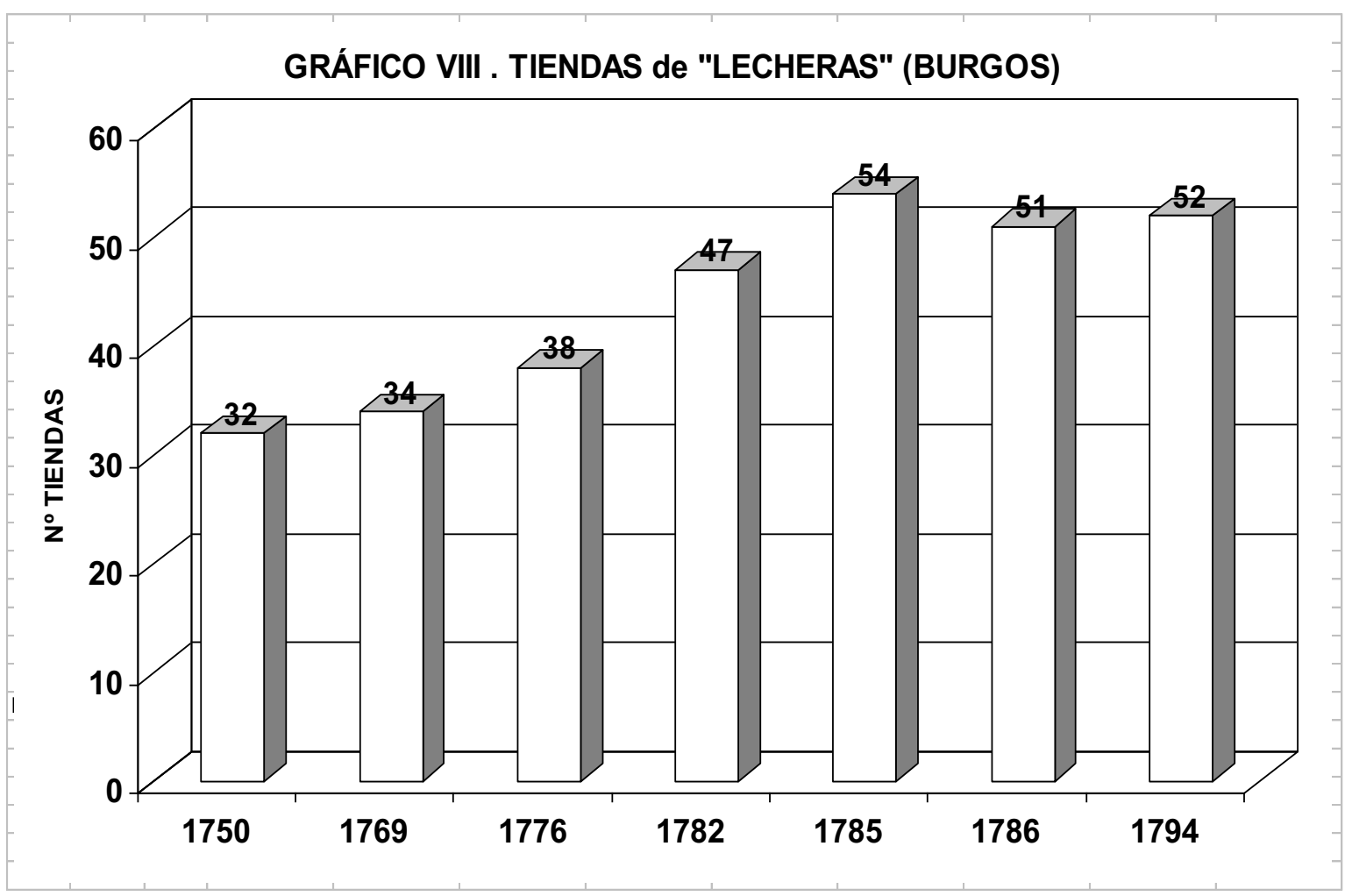

Fuente documental: Archivo Municipal de Burgos. Múltiples Carpetas. Véase Nota 50.

La mediocridad, casi horizontal, de los años anteriores a 1779 se diluye en estos 20 últimos años del Setecientos. Como se comprueba en los gráficos hubo "crecimiento, pero

132 AMB. AG. RO del 20 de marzo de 1778, 51-52.

133 AMB. JPA. RO del 29 de enero de $1773,19 \mathrm{v}$.

134 AMB. AG. RO del 20 de septiembre de 1775, 291rv. 
más en la segunda mitad del siglo que en la primera" ${ }^{135}$. Se dispara la solicitud de licencias, y apertura, de tiendas - GRÁFICO IV y GRÁFICO V - y la expedición de cartas de examen, con sus talleres correspondiente - GRÁFICO VI -. Incluso la producción de cereales, y de trigo en concreto - GRÁFICO VII -, crece abiertamente, aunque su devenir no estaba exento de notables recaídas. Al ritmo de las decisiones gubernamentales de multiplicar el "Hermoseamiento" de las ciudades españolas ${ }^{136}$, se intensifica el reparo y mejora de una gran parte del casco urbano y se financia la construcción de la Casa Consistorial ${ }^{137}$, la cárcel nueva, varios cuarteles ${ }^{138}$, las tahonas, la Escuela de dibujo ${ }^{139}$ o el parador de Vega ${ }^{140}$. A más y mejores cosechas y más atractivos urbanísticos, más talleres artesanos, más tiendas de joyería y de paños y sedas, más mesones, y, por tanto, más consumo de todo tipo de productos. Véase, por ejemplo, el devenir de las "lecheras" - GRÁFICO VIII - o de las tiendas de fruta - GRÁFICO IX -.

Especial significación tiene el rotundo relanzamiento de la expedición de cartas de examen en 1779-1782, si bien después asistimos a un profundo decaimiento (1783-1790) y una recuperación suave pero sostenida (1791-1800). Por lo que toca a la apertura de tiendas, pero sin incluir los talleres artesanos, el panorama es categórico. Se entra en una especie de "montaña rusa" a la española, de variabilidad "catastrófica" en que tan pronto se aprecian fulgurantes repuntes (1779-1783 y 1787-1796) como brutales caídas negativas (1784-1786 y 1797-1799). A la producción agraria le ocurría lo mismo, aunque, la pertinaz sequía obligaba a las típicas rogativas "para Conseguir el beneficio de las aguas"141 o a dar gracias, al poco, "por la abundancia de lluvias" ${ }^{\prime 42}$. El Barón de Maldà hubiera alucinado en Burgos ${ }^{143}$. A pesar de todo, a la ciudad estaba llegando un importante cúmulo de extranjeros - franceses, alemanes, italianos,...-, y catalanes, aragoneses e individuos de múltiples ciudades españolas, algunos de regreso a su hogar natal - por ejemplo, un albéitar y herrador que enfatizaba " me ha sido

\footnotetext{
135 LLOPIS, Enrique y AMARILLA, José Antonio: op. cit., p. 7.

136 Véase, por ejemplo, AMB. AG. RO del 24 de marzo de 1786, 67r.

137 PAYO HERNANZ, René Jesús: Historia de las casas consistoriales en Burgos, Vitoria, Ayuntamiento de Burgos, 2016.

138 CAMARELLO BULLÓN, Concepción: “Cuarteles para Burgos”, en MONTENEGRO DUQUE, Ángel (Dir.): Historia de Burgos III, op. cit., pp. 187-199.

139 IBÁÑEZ PÉREZ, Alberto: Historia de la Academia de Dibujo de Burgos, Burgos, Aldecoa, 1982.

140 SANZ de la HIGUERA, Francisco: "De casa-mesón eclesial a parador consular: Ilustración y zozobra en el Burgos del XVIII”, BIFG, (I) 236, 2008, pp. 199-231 y (II) 237, 2008, pp. 429-466.

${ }_{141}$ AMB. AG. RO del 22 de mayo de 1780, 84v-85r.

142 AMB. AG. RO del 23 de junio de 1780, 115r-116v.

143 D'AMAT, Rafel, Baró de Maldà: Caláis de sastre, Barcelona, Curial, 1988. Véanse ALBEROLA ROMÁ, Armando: "Un “mal año" en la España del siglo XVIII", en HUETZ de LEPM, Xavier y LUIS, Jean-Phillippe (Eds.): Surtir du labyrinthe, Madrid, Casa de Velázquez, 2012, PP. 325-346 y "Meteorología y desastre en la España de Carlos IV”, en de LORENZO ÁLVAREZ, Elena (Ed.): La época de Carlos IV (1788-1808), Oviedo, Ediciones Trea, 2009, pp. 115-129.
} 
forzoso benirme otra vez a este pueblo por Salud ${ }^{p 144}$. Las guerras contra Francia, contra Inglaterra y contra Rusia inyectaron en la ciudad de Burgos la presencia de múltiples acantonamientos militares, precisados de asistencia hospitalaria. Eran bocas que alimentar y cuerpos que vestir. Una parte notable de las nuevas tiendas fue gestionada por soldados retornados de los conflictos $^{145}$.

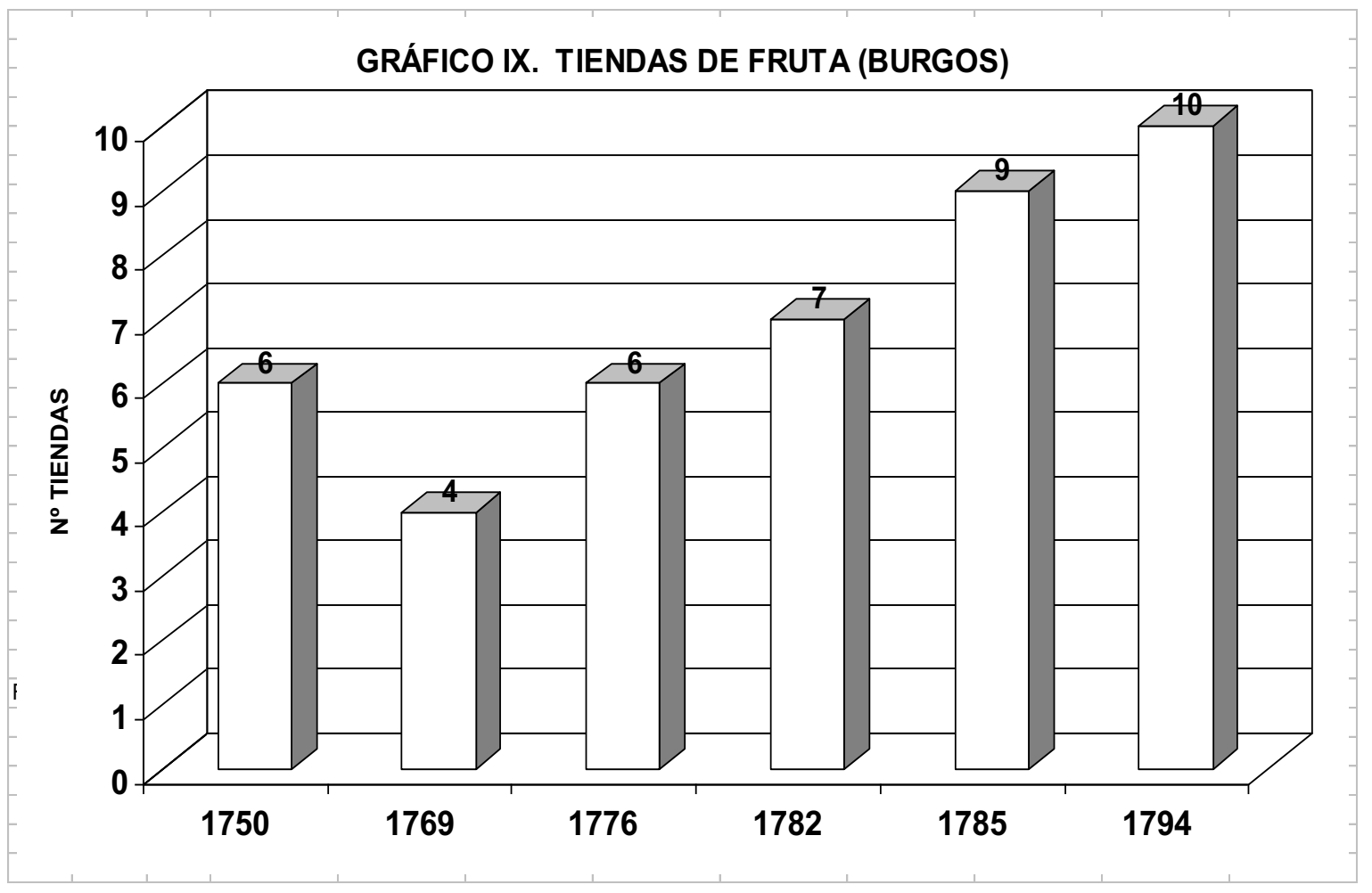

Fuente documental: Archivo Municipal de Burgos. Múltiples Carpetas. Véase Nota 50.

En este período se alternan las cosechas más nutridas del siglo con otras marcadas por graves pérdidas de producto. Se reiteran las quejas "por causa de haber sido cortas las cosechas de los años proximos pasados [y] se allan sin grano para poder continuar las labores del campo y mantenerse y sin arbitrio para poderlo comprar, a no ser bendiendo sus Ganados de labranza a bajos precios" ${ }^{2146}$. Niveles de renta y precios de los cereales bajos y buenas cosechas favorecen el aumento del poder adquisitivo de los pequeños y medianos productores, así como de los consumidores de la ciudad. Lo contrario merma poderosamente el consumo, y más si la inflación limita el gasto, "con consideración a la notoria altura que han tomado todos los comestibles y demas jeneros de todas

144 AMB. AG. RO del 24 de julio de 1780, 141rv.

145 AMB. AG. RO del 14 de noviembre de 1796, 225v-226r.

146 AMB. AA. RO del 8 de junio de 1786, 110v. 
especies" ". Se alternaron años secos y años "búmedos, que son muchos, no solo con frecuentes lluvias que se experimentan sino por lo tardío de la Cosecha" ${ }^{\text {148 }}$. La indignación se expresaba de manera airada por el "por el poco consumo (...) que se experimenta (...) ocasionado mucha parte por los bastantes figones que se han establecido y subida de la renta en que lleba la Casa que habita"149 - GRÁFICO X -. La pugna entre tenderos y mercaderes dejaba, en la crisis finisecular, la ciudad preñada de ascensos y derrotas - GRÁFICO XI -.

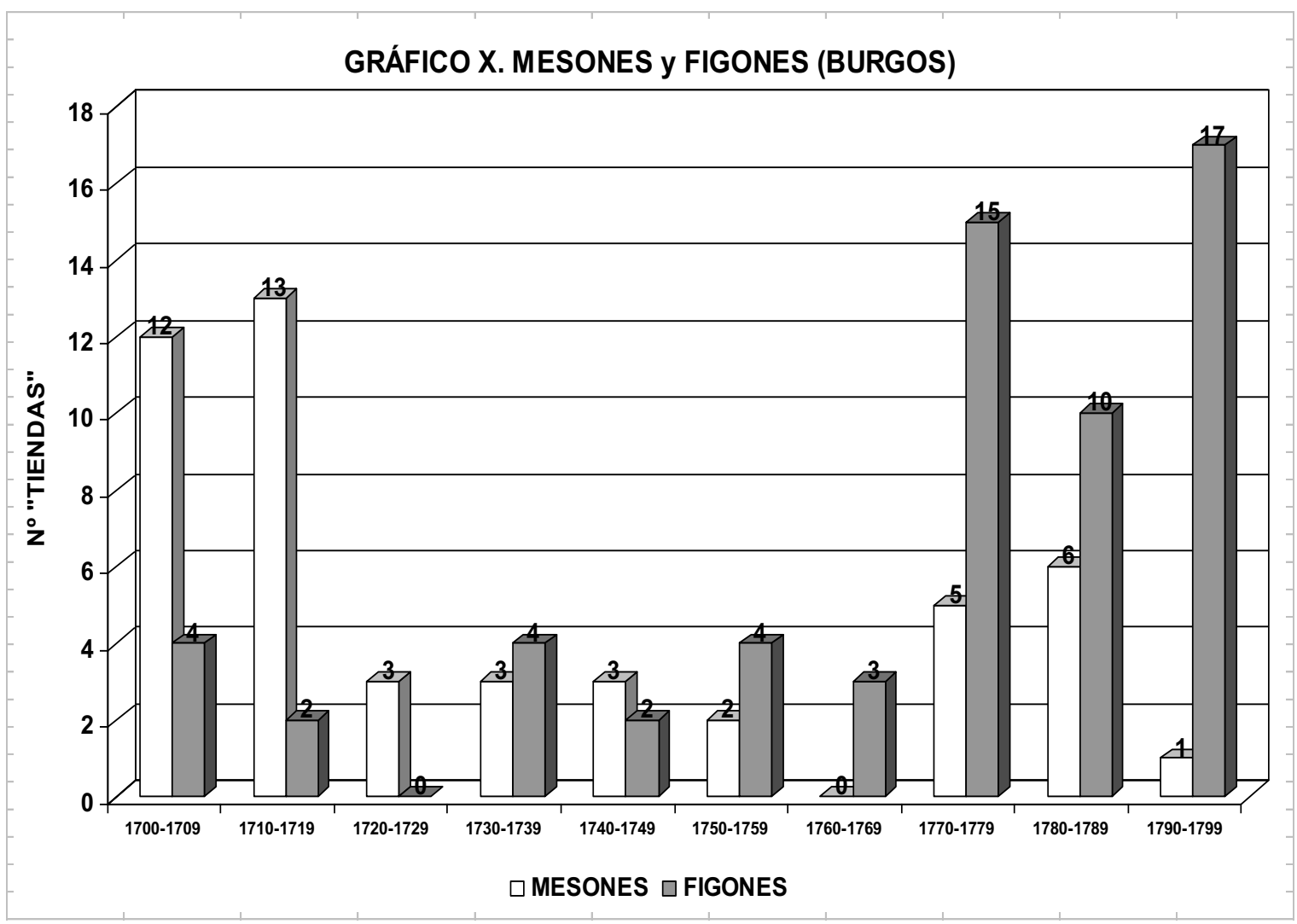

Fuente documental. Archivo Municipal de Burgos. Actas de Gobierno, Abastos y Junta de Propios.

La "Exorbitante suvida de precios" 150 generó una diabólica, y enfermiza, retroalimentación entre oferta y demanda que empobrecía a quienes disponían de cada vez menos para consumir y acrecentaba las talegas de los más afortunados "empresarios".

147 AMB. AA. RO del 10 de junio de 1788, 126v.

148 AMB. AA. RO del 15 de marzo de 1792, 124r.

149 AMB. AA. RO del 25 de junio de 1792, 261r.

150 AMB. AA. RO del 17 de junio de 1797, 146v-147r. 


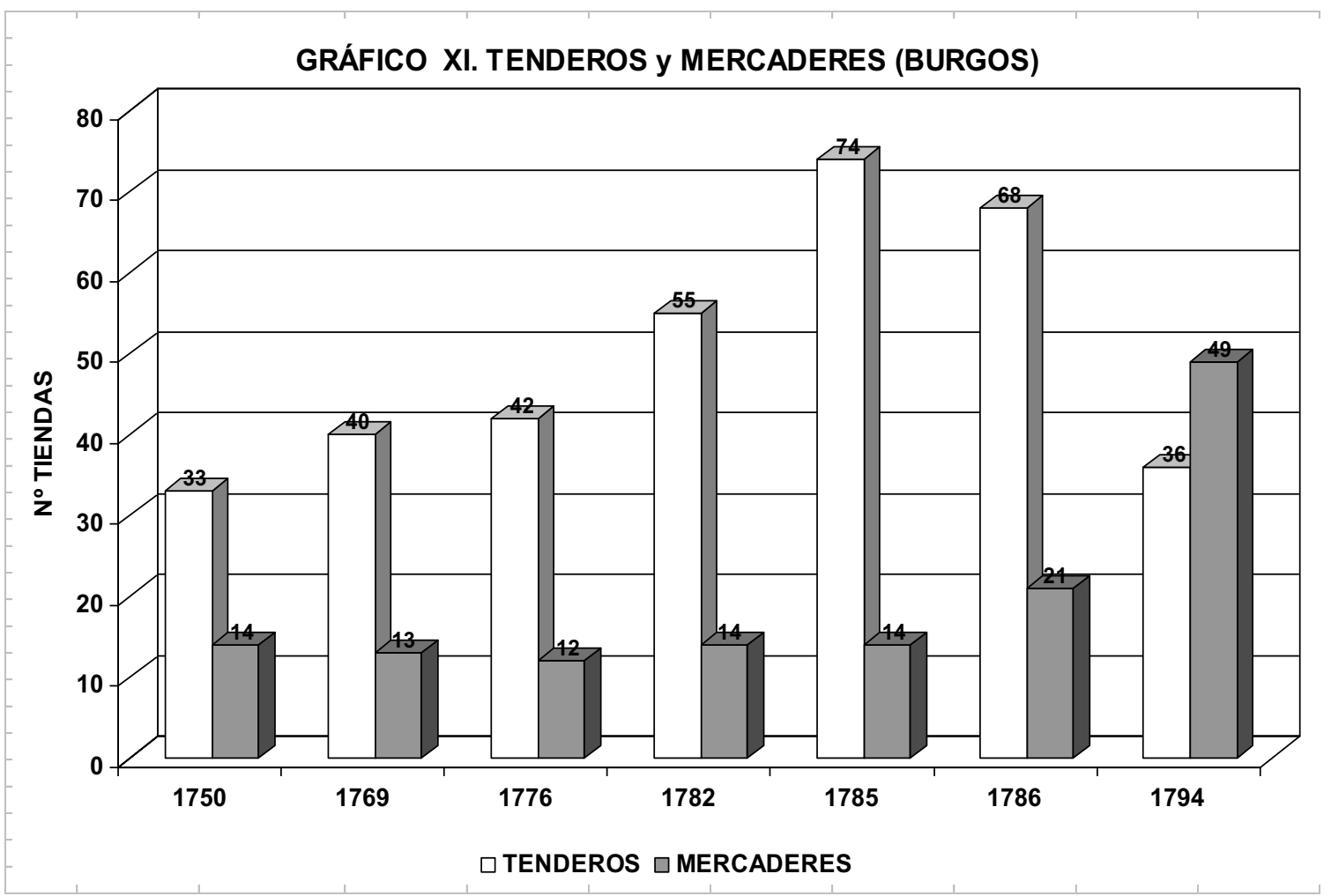

Fuente documental: Archivo Municipal de Burgos. Múltiples Carpetas. Véase Nota 50.

\section{A modo de conclusión.}

La reconstrucción del acontecer económico del Burgos del Setecientos precisa del análisis de parámetros novedosos, algunos de los cuales han sido exhumados en estas páginas - por ejemplo, la concesión de licencia de apertura de tiendas y talleres y la obtención de la maestría artesanal en el seno de los gremios y "tratos" de dicha ciudad castellana en el devenir del Setecientos -. Dado que, en el momento actual, contamos con pocos estudios al respecto, este trabajo pretende convertirse en un modelo de referencia para la comunidad de investigadores en Historia Moderna. El manejo simultáneo de apertura de tiendas y establecimiento de talleres artesanos, con el telón de fondo de la producción agrícola y el impacto del tiempo y el clima en la calidad económica de la ciudad, postula un acercamiento dialéctico al por qué sucedía lo que sucedía en la micro-economía de las ciudades del Setecientos. El objetivo esencial de estas páginas se orienta, en efecto, al descubrimiento de cómo auscultar las problemáticas económicas de una ciudad preindustrial a través del descubrimiento del dinamismo o declive de la apertura de tiendas y talleres artesanos y de la cuantificación de cuántos oficiales adquirieron el grado de maestros en la industria urbana.

Aunque no exento de múltiples problemas metodológicos y hermenéuticos, la diacronía de las tiendas y los talleres nos devela que los establecimientos comerciales y de 
servicios y la industria burgalesa del XVIII respondían, aunque no de manera mecánica, por supuesto, a los diferentes momentos de mejoría o de empeoramiento de las condiciones climáticas y de las producciones agrícolas. Los responsables gremiales, con el concurso del Concejo, y los "emprendedores" comerciales sopesaban, de forma crítica, las posibilidades de aumentar el número de talleres o de tiendas en función de las capacidades adquisitivas y el devenir de los precios de los cereales y de los comestibles esenciales. Lo cierto es que, a lo largo del Setecientos - después del calamitoso siglo XVII, el "siglo de hierro" - percibimos a través de los diferentes gráficos como mejora, aunque con vaivenes estremecedores, el número de quienes se arriesgan a abrir tiendas al público - en especial en lo tocante al pequeño comercio de joyería y especiería y a las lonjas de paños y sedas, además de numerosos mesones, figones y locales para la venta de bebidas - y la realización de exámenes de maestría - sobre todo para los oficiales de sastre, zapateros de obra prima, tejedores de lienzos, herreros o confiteros -.

Las etapas de crisis climáticas y agrícolas generaban en el tejido productivo sesgos depresivos que retraían las inversiones en lo comercial y en la necesidad de reemplazar a los maestros artesanos fallecidos o de ampliar la disponibilidad de talleres gremiales. Los desperfectos en los bolsillos de los consumidores, y de los "empresarios" comerciales y artesanales, mermaba la capacidad adquisitiva y el ánimo imprescindible para arriesgar el capital doméstico, y no arruinarse y fallecer en el intento. Las recesiones, y más con la brutalidad de las crisis económicas más profundas y destructivas, desanimaban la solicitud de licencias y la ampliación de la nómica de talleres artesanos. El crecimiento económico, los bajos precios y la dulzura climática impelían a la población a consumir, a demandar más y más productos, y a los inversores a ofertar más y más establecimientos y garitos.

La apertura de tiendas y la consecución de la maestría para una parte de los oficiales de los talleres artesanos se conforman como sólidos "proxy data” en la averiguación de cuál fue el acontecer de la economía de las ciudades preindustriales, en especial en el XVIII. Sus zigzagueos delatan poderosos, y sórdidos, balanceos de los parámetros más oscuros de las capacidades de inversión, de producción y de demanda. 